\title{
MANCHESTER
}

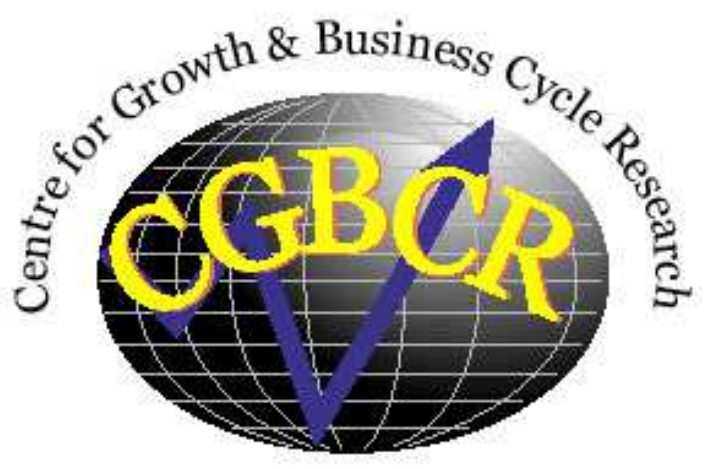

Discussion Paper Series

\section{Macroprudential Policy Coordination in a Currency Union}

By

\section{Pierre-Richard Agénor and Pengfei Jia}

Centre for Growth and Business Cycle Research, Economic Studies, University of Manchester, Manchester, M13 9PL, UK

June 2017

Number 235

Download paper from:

http://www.socialsciences.manchester.ac.uk/cgbcr/discussionpape rs/index.html 


\title{
Macroprudential Policy Coordination in a Currency Union
}

\author{
Pierre-Richard Agénor* and Pengfei Jia**
}

\begin{abstract}
This paper evaluates, using a game-theoretic approach, the benefits of coordinating macroprudential policy (in the form of reserve requirements) in a two-country model of a currency union with credit market imperfections. Financial stability is first defined in terms of the volatility of the credit-to-output ratio. The gains from coordination are measured by comparing outcomes under a centralized regime, where a common regulator sets the required reserve ratio to minimize union-wide financial volatility, and a decentralized (Nash) regime, where each country regulator sets that ratio to minimize its own policy loss. Experiments show that, under asymmetric real and financial shocks, the gains from coordination are significant at the union level. Moreover, these gains are higher when the common and national regulators have asymmetric preferences with respect to output stability, when financial markets are more integrated, and when the degree of asymmetry in credit markets between members is larger. Implications of the analysis for macroprudential policy coordination in the euro area are also discussed.
\end{abstract}

JEL Classification Numbers: E58, F41, F45

${ }^{*}$ School of Social Sciences, University of Manchester; **University of Manchester. We are grateful to Christoph Himmels, Leonidas Koutsougeras, participants at the 2017 Annual Conference of the Royal Economic Society in Bristol, and especially Gianni Lombardo for discussions and comments on an earlier draft. However, we bear sole responsibility for the views expressed in this paper. Appendices $\mathrm{A}$ and $\mathrm{B}$ are available upon request. 


\section{Introduction}

Increased interconnectedness of financial institutions and markets, and more highly correlated financial shocks, have intensified cross-border spillovers-as well as so-called "spillbacks," as documented by the Bank for International Settlements (2016) and the International Monetary Fund (2016) — and have led to renewed calls to strengthen prudential regulation and supervision of financial institutions, both within and between countries. These policies have been viewed by some observers to be essential to mitigate the substantial risks associated with international financial integration, and the potentially large economic costs that countries may face when crises occur and are propagated across borders.

At the same time, there has been increased recognition that differences in national regulatory regimes and policies across countries can themselves become a source, and conduit for, international spillovers. In particular, by triggering cross-border regulatory arbitrage, differences in macroprudential rules may lead to sharp swings in capital flows and magnify the international propagation of real and financial shocks, through changes in asset prices and collateral values. ${ }^{1}$ When financial cycles are not well synchronized across countries, or systemic intermediaries can evade at little cost policy actions taken by national authorities, the overall combination of macroprudential policies may be suboptimal - even when each country's policy is optimal at the national level. As a result, financial instability risks may worsen at the level of the global economy. The question arises therefore as to whether formal coordination of these policies between countries - beyond the reciprocity agreements promoted by the Basel III Accord in the context of capital requirements, for instance - would not improve global financial stability and welfare.

Recent analytical contributions have indeed identified several channels through which cross-country coordination of macroprudential policies could mitigate the adverse effects of cross-border spillovers and raise welfare. ${ }^{2}$ Some of these contributions, in-

\footnotetext{
${ }^{1}$ See Aiyar et al. (2014) and Beirne and Friedrich (2014) for empirical evidence on the channels through which national macroprudential policies can generate cross-border spillovers.

${ }^{2}$ Another strand of literature has focused on the scope for, and the benefits from, international coordination of monetary policies. See Pappa (2004), Benigno and Benigno (2008), Liu and Pappa (2008), Coenen et al. (2009), Kolasa and Lombardo (2014), Banerjee et al. (2016), and Fujiwara and
} 
cluding those of Bengui (2014), Jeanne (2014), Korinek (2014, 2017), and Kara (2016), are based on small analytical models. A growing number of others are based on twocountry dynamic stochastic general equilibrium (DSGE) models with financial market imperfections and include Kollmann et al. (2011), Kollmann (2013), Rubio (2014), Cuadra and Nuguer (2014), Quint and Rabanal (2014), Mendicino and Punzi (2014), Brzoza-Brzezina et al. (2015), Palek and Schwanebeck (2015), Poutineau and Vermandel (2015), and Rubio and Carrasco-Gallego (2016). ${ }^{3}$

Of particular interest to us in this study are those contributions focusing on a currency union with national policymakers and a common central bank, both of which possibly taking on a macroprudential regulatory role as an additional mandate. A key question in that context has been the level (national or supranational) at which macroprudential regulation should be conducted. This issue is particularly important in a currency union with a one-size-fits-all monetary policy and business cycles are not fully synchronized - prompting some observers to argue that pro-active domestic macroprudential policies are needed not only from the perspective of financial stability but also output stability, given the impact of macroprudential instruments on credit, and the demand- and supply-side links between credit and economic activity.

Rubio (2014) for instance explored how loan-to-value (LTV) ratios, endogenously related to output and house prices, should be set in such as an environment. Her results emphasized the importance of asymmetries for the conduct of macroprudential policies in a monetary union, especially when heterogeneity results in differences in aggregate volatility. In the same vein, Rubio and Carrasco-Gallego (2016) found that, compared to the case where an LTV macroprudential policy is implemented at the level of a single member country, the welfare gain is larger if all members of the union (or a common supranational entity) implement it in coordinated fashion. At the same time, the additional welfare gain from introducing country-specific macroprudential is

Teranishi (2017) for specific contributions, as well as Taylor (2013), Eichengreen (2014) and Engel (2016) for a broader perspective. Even though many of the models used in that literature do not account explicitly for financial frictions and regulatory regimes, some of their results (as discussed later) are relevant for the ongoing debate on macroprudential policy coordination across countries.

${ }^{3}$ Some of these contributions have also looked at the combination of monetary and macroprudential policies (see Mendicino and Punzi (2014) and Quint and Rabanal (2014)), but this is beyond the scope of this paper. 
small. ${ }^{4}$ Brzoza-Brzezina et al. (2015) also examined the effectiveness of LTV ratios as a macroprudential policy instrument, linked to changes in credit, house prices, and output, under the assumption that core and periphery union members are impacted by asymmetric shocks. Their results showed that centralized macroprudential policy can substantially lower the magnitude of credit and output fluctuations in the periphery. They also found that decentralized macroprudential policy is more successful than a common policy from a welfare perspective.

Quint and Rabanal (2014) focused instead on the case where a "generic" macroprudential instrument influences credit market conditions by affecting directly the fraction of liabilities that banks can lend. They found that, under a variety of scenarios, the introduction of a macroprudential rule would help to reduce macroeconomic volatility and improve union-wide welfare, thereby partially substituting for the lack of national monetary policies. Palek and Schwanebeck (2015) also considered the case where the regulatory policy instrument affects the borrowing costs faced by entrepreneurs. Their results showed that macroprudential policy is effective at mitigating fluctuations of the economies at the union level under a variety of scenarios, thereby improving welfare.

The purpose of this paper is twofold. First, it aims to contribute to a better understanding of the cross-border spillover effects of macroprudential policy in a currency union where credit and capital markets are imperfect and housing plays a key role as collateral. Second, it aims to quantify the gains (or lack thereof) associated with countercyclical macroprudential policy coordination in a currency union, relative to the case where countries pursue independently their own policies, and to assess how these gains depend on how financial stability is measured, the degree of asymmetry in preferences between national regulators and the common regulator, the degree of financial integration, and the degree of heterogeneity in credit market imperfections across countries.

In contrast to the existing literature, we focus on reserve requirements as the instrument of macroprudential regulation. In recent years policymakers in a number of

\footnotetext{
${ }^{4}$ In practice, however, it is hard to think of sectoral macroprudential instruments (such as LTV ratios or debt-to-income ratios) as being set by a centralized institution in a currency union, because of significant institutional differences between national housing markets.
} 
countries have indeed used reserve requirements to mitigate credit fluctuations and promote macroeconomic and financial stability - not only in middle-income countries, where time and again they have been used aggressively, but in some advanced economies as well (see Agénor et al. (2015) and Cerutti et al. (2017)). They have also been advocated as a way of taxing the negative systemic externality associated with credit booms in these economies (see Kashyap and Stein (2012)). ${ }^{5}$ Our analysis is thus both positive and normative, in the sense that it aims to assess whether such a policy could also prove to be an effective countercyclical instrument in a monetary union.

Also in contrast with most existing contributions, we address this issue in an explicit game-theoretic framework. This allows us to account for strategic interactions between countries when they choose their policies in the absence of cooperation. Specifically, we compare the properties of two alternative, explicit mandates to achieve financial stability: macroprudential policy, in the form of a simple, implementable rule, delegated to a common regulator (the cooperative equilibrium or centralized regime), and macroprudential policy delegated to the individual member countries (the noncooperative Nash equilibrium or decentralized regime), with the common central bank retaining control of monetary policy. This separation of mandates is consistent with the fact that, in practice, distinct institutions are often made responsible for achieving narrower goals on the grounds of accountability (see Committee on the Global Financial System (2016)). Our focus is on understanding whether delegating the setting of the macroprudential instrument to the common central bank helps to reduce the magnitude of cross-border spillovers and stabilize better than when individual countries pursue their own policies. We begin with the case where the two countries are perfectly symmetric and shocks, real and financial, originate in the home country only. We also initially measure financial stability in terms of the volatility of the credit-to-output ratio.

A numerical comparison of the decentralized regime (in which regulators in each country set the required reserve ratio to minimize own financial volatility) and the centralized regime (where the common regulator sets either a uniform ratio or separate

\footnotetext{
${ }^{5}$ More generally, the idea that macroprudential regulation can be modeled as a tax (on deposits, like reserve requirements, or on loans or bank net worth) has appeared in other contributions as well. See Agénor et al. (2017) for a discussion.
} 
ratios to minimize union-wide financial volatility) shows that the gains from coordination from the perspective of the home country (where the shocks occur) or the union as a whole are significant in response to financial shocks. Intuitively, the ability of the common regulator to internalize spillovers to the foreign country, and spillbacks to the home country, when setting the common required reserve ratio generates a stabilization benefit that translates into a lower policy loss. Moreover, when member countries are faced with asymmetric shocks, a one-size-fits-all policy of setting a uniform required reserve ratio is suboptimal compared to separate instrument setting. However, when shocks are real in nature the country of origin may be worse off under cooperationeven if at the same time the union as a whole benefits from it. If transfers from winners to losers cannot be enforced, cooperation in such conditions can be sustained only with a collective binding political commitment.

We also find that the gains from coordination are stronger when the national and common regulators are both concerned with output stability as well, but the common regulator attaches a higher weight to financial stability than the national regulators. The gains from coordination, at both the union and each country's levels, tend to increase also with the degree of financial market integration, because the common regulator is able to internalize the effects of greater integration on cross-border spillovers through financial markets. Finally, we find that the relative gain from coordination, from the perspective of the home country, tends to increase with the degree of asymmetry in credit markets between the member where the shocks originate and the other member of the union.

The remainder of the paper proceeds as follows. Section 2 describes the model, which features imperfect capital mobility and imperfect substitutability between deposits and central bank borrowing - a critical assumption for generating a role for reserve requirements. The equilibrium and some key features of the steady state are discussed in Section 3, and a core parameterization is presented in Section 4. Our goal here is not to match any particular set of data, but rather to characterize (using as much as possible standard parameter values) some qualitative properties of the dynamic path of the model. Nevertheless, our choice of parameters reflects to a significant extent recent estimates for the euro area. The results of asymmetric productivity and 
financial shocks are described in Section 5. The optimal, loss-minimizing policy under the two alternative mandates described earlier are examined in Section 6. The macroprudential policy instrument that we consider, as noted earlier, is reserve requirements. A simple implementable rule, linking changes in the required reserve ratio to deviations in the credit-to-output ratio, is defined, both at the national and union-wide levels. Sensitivity analysis is reported in Section 7, in order to examine how the model's structural features affect the gains from coordination. We consider, in particular, the degree of financial integration, asymmetry in country size, and the degree of credit market imperfections. Even though (as noted earlier) the model is not built and parameterized to match exactly the key features of the euro area, the broad policy implications of our analysis for that entity are discussed in Section 8. The last section discusses some potentially fruitful directions in which our analysis can be extended.

\section{The World Economy}

The world economy consists of two countries only, called home and foreign, and are joined in a currency union. Thus, both countries use the same currency and delegate their monetary policy to a common monetary authority. Countries are symmetric in all respects except, as discussed later on, for the frictions that characterize their credit market and their size. They trade in goods and government bonds, but markets in cash and credit are segmented. Thus, financial markets are imperfectly integrated.

Each country is populated by six categories of agents: a representative household, a continuum of monopolistic (IG) firms producing intermediate goods, a nontradable final good (FG) producer, a capital good (CG) producer, a commercial bank, and the government. There is also a common central bank and domestic financial regulators, which may or may not (depending on the policy regime) set reserve requirement rates at the national level. When macroprudential policy coordination is required, the common central bank acts as the union-wide financial regulator as well. Neither firms nor banks, in either country, can lend and borrow internationally.

Each country uses capital and labor to produce a continuum of intermediate goods, which are imperfect substitutes to a continuum of imported intermediate goods. As 
in a number of contributions (see Kollmann (2003), Bergin et al. (2007), Huang and Liu (2007), and Gong et al. (2016) for instance), trade within the union occurs only at the level of intermediate goods and both categories of goods are combined in each country to produce a homogeneous final good. These goods are used only for local consumption and investment. Capital and labor are not mobile internationally.

In what follows we describe the home economy; where relevant, descriptions of the foreign economy are also provided. ${ }^{6}$

\subsection{Households}

Households in both countries have identical preferences. The objective of the representative household in the home country is to maximize

$$
U_{t}^{H}=\mathbb{E}_{t} \sum_{s=0}^{\infty} \beta^{s}\left\{\frac{\left(C_{t+s}^{H}\right)^{1-\varsigma^{-1}}}{1-\varsigma^{-1}}+\eta_{N} \ln \left(1-N_{t+s}^{H}\right)+\ln \left[\left(x_{t+s}^{H}\right)^{\eta_{x}}\left(A_{t+s}^{H}\right)^{\eta_{A}}\right\}\right.
$$

where $C_{t}^{H}$ is consumption of the home final good, $N_{t}^{H}=\int_{0}^{1} N_{t}^{H, j} d j$, the share of total time endowment (normalized to unity) spent working, with $N_{t}^{H, j}$ denoting the number of hours of labor provided to home IG producer $j, x_{t}^{H}$ a composite index of real monetary assets, $A_{t}^{H}$ the stock of housing, $\beta \in(0,1)$ a discount factor, $\varsigma>0$ the intertemporal elasticity of substitution in consumption, $\mathbb{E}_{t}$ the expectation operator conditional on the information available at the beginning of period $t$, and $\eta_{N}, \eta_{x}, \eta_{A}>0$.

The composite monetary asset consists of real cash balances, $m_{t}^{H P}$, and real bank deposits, $d_{t}^{H}$, both measured in terms of the price of home final output, $P_{t}^{H}$ :

$$
x_{t}^{H}=\left(m_{t}^{H P}\right)^{\nu}\left(d_{t}^{H}\right)^{1-\nu} . \quad \nu \in(0,1)
$$

The household's flow budget constraint is

$$
\begin{gathered}
m_{t}^{H P}+d_{t}^{H}+b_{t}^{H H}+b_{t}^{H F}+z_{t}^{H A} \Delta A_{t}^{H} \\
=w_{t}^{H} N_{t}^{H}-T_{t}^{H}-C_{t}^{H}+\frac{m_{t-1}^{H P}}{1+\pi_{t}^{H}}+\left(\frac{1+i_{t-1}^{H D}}{1+\pi_{t}^{H}}\right) d_{t-1}^{H}+\left(\frac{1+i_{t-1}^{H B}}{1+\pi_{t}^{H}}\right) b_{t-1}^{H H} \\
+\left(1+i_{t-1}^{F}\right) b_{t-1}^{H F}+J_{t}^{H D}+J_{t}^{H K}+J_{t}^{H B},
\end{gathered}
$$

\footnotetext{
${ }^{6}$ Throughout the paper, the superscripts $H$ and $F$ are used to refer to home and foreign country variables, respectively.
} 
where $z_{t}^{H A}=P_{t}^{H A} / P_{t}^{H}$ is the real price of housing (with $P_{t}^{H A}$ the nominal price), $1+\pi_{t}^{H}=P_{t}^{H} / P_{t-1}^{H}, b_{t}^{H H}\left(b_{t}^{H F}\right)$ real holdings of one-period, noncontingent home (homecurrency value of foreign) government bonds by domestic households, $i_{t}^{H D}$ the interest rate on bank deposits, $i_{t}^{H B}$ the interest rate on home government bonds, $i_{t}^{F}$ the premium-adjusted (or effective) interest rate on foreign government bonds, $w_{t}^{H}$ the economy-wide real wage, $T_{t}^{H}$ real lump-sum taxes, $J_{t}^{H I}, J_{t}^{H K}$, and $J_{t}^{H B}$, end-of-period profits of the IG producer, the CG producer, and the commercial bank, respectively. For simplicity, housing does not depreciate.

Home households face intermediation costs when taking a position on the foreign bond market. The effective rate of return on foreign bonds is given by

$$
1+i_{t}^{F}=\left(1+i_{t}^{F B}\right)\left(1+\theta_{t}^{H F}\right)
$$

where $i_{t}^{F B}$ is the unadjusted foreign bond rate and $\theta_{t}^{H F}$ a premium, which falls with the household's own stock of foreign bonds:

$$
\theta_{t}^{H F}=-\frac{\theta_{0}^{B}}{2} b_{t}^{H F}
$$

with $\theta_{0}^{B}>0$ a symmetric cost parameter.

The home household maximizes (1) with respect to $C_{t}^{H}, N_{t}^{H}, m_{t+1}^{H P}, d_{t+1}^{H}, b_{t+1}^{H H}, b_{t+1}^{H F}$, and $A_{t+1}^{H}$, subject to (3), (4), and (5), taking period- $t-1$ variables as well as $w_{t}^{H}, T_{t}^{H}$, and real profits as given. The first-order conditions are

$$
\begin{gathered}
\mathbb{E}_{t}\left[\left(\frac{C_{t+1}^{H}}{C_{t}^{H}}\right)^{1 / \varsigma}\right]=\beta \mathbb{E}_{t}\left(\frac{1+i_{t}^{H B}}{1+\pi_{t+1}^{H}}\right), \\
N_{t}^{H}=1-\frac{\eta_{N}\left(C_{t}^{H}\right)^{1 / \varsigma}}{w_{t}^{H}}, \\
m_{t}^{H P}=\frac{\eta_{x} \nu\left(C_{t}^{H}\right)^{1 / \varsigma}\left(1+i_{t}^{H B}\right)}{i_{t}^{H B}}, \\
d_{t}^{H}=\frac{\eta_{x}(1-\nu)\left(C_{t}^{H}\right)^{1 / \varsigma}\left(1+i_{t}^{H B}\right)}{i_{t}^{H B}-i_{t}^{H D}}, \\
z_{t}^{H A} A_{t}^{H}=\left\{1-\mathbb{E}_{t}\left(\frac{1+\pi_{t+1}^{H A}}{1+i_{t}^{H B}}\right\}^{-1} \eta_{A}\left(C_{t}^{H}\right)^{1 / \varsigma},\right. \\
b_{t}^{H F}=\frac{i_{t}^{F B}-i_{t}^{H B}}{\theta_{0}^{B}\left(1+i_{t}^{F B}\right)},
\end{gathered}
$$


where $1+\pi_{t+1}^{H A}=P_{t+1}^{H A} / P_{t}^{H A}$.

Foreign households face a resource allocation problem similar to the one faced by home households. In particular, their demand for home bonds is given by

$$
b_{t}^{F H}=\frac{i_{t}^{H B}-i_{t}^{F B}}{\theta_{0}^{B}\left(1+i_{t}^{H B}\right)} .
$$

Equations (11) and (12) imply that interest parity $\left(i_{t}^{H B}=i_{t}^{F B}\right)$, or perfect capital mobility, obtains when $\theta_{0}^{B} \rightarrow 0$. Thus, as discussed later, the impact of financial integration on the gains from coordination can be assessed by varying $\theta_{0}^{B}$.

\subsection{Final Good Production}

To produce the home final good, $Y_{t}^{H}$, a basket of domestically-produced differentiated intermediate goods sold at home, $Y_{t}^{H H}$, is combined with a basket of imported intermediate goods produced abroad (that is, foreign exports), $Y_{t}^{F H}$ :

$$
Y_{t}^{H}=\left[\Lambda_{I}\left(Y_{t}^{H H}\right)^{(\eta-1) / \eta}+\left(1-\Lambda_{I}\right)\left(Y_{t}^{F H}\right)^{(\eta-1) / \eta}\right]^{\eta /(\eta-1)},
$$

where $0.5<\Lambda_{I}<1$, to capture home bias in final good production, and $\eta>0$ is the elasticity of substitution between the two baskets, each of which defined as

$$
Y_{t}^{i}=\left\{\int_{0}^{1}\left[Y_{j t}^{i}\right]^{\left(\theta_{i}-1\right) / \theta_{i}} d j\right\}^{\theta_{i} /\left(\theta_{i}-1\right)} \cdot i=H H, F H
$$

In this expression, $\theta_{i}>1$ is the elasticity of substitution between intermediate home goods among themselves $(i=H H)$, and imported goods among themselves $(i=F H)$, and $Y_{j t}^{i}$ is the quantity of type- $j$ intermediate good of category $i$, with $j \in(0,1)$.

Cost minimization yields the demand functions for each variety $j$ of intermediate goods:

$$
Y_{j t}^{i}=\left(\frac{P_{j t}^{i}}{P_{t}^{i}}\right)^{-\theta_{i}} Y_{t}^{i}, \quad i=H H, F H
$$

where $P_{j t}^{H H}\left(P_{j t}^{F H}\right)$ is the home price of home (imported) intermediate good $j$, and $P_{t}^{H H}$ and $P_{t}^{F H}$ are price indices, which are given by

$$
P_{t}^{i}=\left\{\int_{0}^{1}\left(P_{j t}^{i}\right)^{1-\theta_{i}} d j\right\}^{1 /\left(1-\theta_{i}\right)} \cdot i=H H, F H
$$


Demand functions for baskets of home and foreign goods are

$$
Y_{t}^{H H}=\Lambda_{I}^{\eta}\left(\frac{P_{t}^{H H}}{P_{t}^{H}}\right)^{-\eta} Y_{t}^{H}, \quad Y_{t}^{F H}=\left(1-\Lambda_{I}\right)^{\eta}\left(\frac{P_{t}^{F H}}{P_{t}^{H}}\right)^{-\eta} Y_{t}^{H},
$$

where $P_{t}^{H}$ is the price of home final output, given by

$$
P_{t}^{H}=\left[\Lambda_{I}^{\eta}\left(P_{t}^{H H}\right)^{1-\eta}+\left(1-\Lambda_{I}\right)^{\eta}\left(P_{t}^{F H}\right)^{1-\eta}\right]^{1 /(1-\eta)},
$$

with an analogous expression for the price of final output abroad, $P_{t}^{F}$.

Assuming no transportation costs between countries, and no rigidities, the law of one price implies that the home price of imported good $j$ is given by

$$
P_{j t}^{F H}=P_{j t}^{F F}
$$

where $P_{j t}^{F F}$ is the price of foreign intermediates, set in the foreign country. However, because of home bias in production, $P_{t}^{H}$ and $P_{t}^{F}$ in general differ from each other; their ratio defines the real exchange rate.

\subsection{Production of Intermediate Goods}

Home output of intermediate home good $j, Y_{j t}^{H I}$, is sold on a monopolistically competitive market and is produced by combining home labor, $N_{j t}^{H}$, and beginning-of-period home capital, $K_{j t}^{H}$ :

$$
Y_{j t}^{H I}=\epsilon_{t}^{Y}\left(N_{j t}^{H}\right)^{1-\alpha}\left(K_{j t}^{H}\right)^{\alpha}
$$

where $\alpha \in(0,1)$ and $\epsilon_{t}^{Y}$ is a common technology shock, which follows an $A R(1)$ process of the form $\epsilon_{t}^{Y}=\epsilon_{t-1}^{\rho^{Y}} \exp \left(\xi_{t}^{Y}\right)$, where $\rho^{Y} \in(0,1), \xi_{t}^{Y} \sim \mathbf{N}\left(0, \sigma_{\xi^{Y}}\right)$, and a ' ' is used to denote a steady-state value.

Capital is rented from the $\mathrm{CG}$ producer at the rate $r_{t}^{H K}$ and paid for after the sale of output. Cost minimization yields the capital-labor ratio and the unit real marginal cost, $m c_{t}^{H}$, as

$$
\begin{aligned}
\frac{K_{j t}^{H}}{N_{j t}^{H}} & =\left(\frac{\alpha}{1-\alpha}\right)\left(\frac{w_{t}^{H}}{r_{t}^{H K}}\right) \quad \forall i \\
m c_{t}^{H} & =\frac{\left(w_{t}^{H}\right)^{1-\alpha}\left(r_{t}^{H K}\right)^{\alpha}}{\alpha^{\alpha}(1-\alpha)^{1-\alpha} \epsilon_{t}^{Y}}
\end{aligned}
$$


Each firm $j$ chooses a sequence of prices so as to maximize the discounted present value of its profits:

$$
\left\{P_{j t+s}^{H H}\right\}_{s=0}^{\infty}=\arg \max \mathbb{E}_{t} \sum_{s=0}^{\infty} \beta^{s} \lambda_{t+s} J_{j t+s}^{H I},
$$

where $\beta^{s} \lambda_{t+s}$ measures the marginal utility value to the representative home household of an additional unit of real profits, $J_{j t+s}^{H I}$, received in the form of dividends at $t+s$. In Rotemberg fashion, prices are costly to adjust; profits are thus defined as

$$
J_{j t}^{H I}=\left(\frac{P_{j t}^{H H}}{P_{t}^{H H}}\right) Y_{j t}^{H I}-m c_{t}^{H} Y_{j t}^{H I}-\frac{\phi_{I}}{2}\left(\frac{P_{j t}^{H H}}{P_{j t-1}^{H H}}-1\right)^{2} Y_{t}^{H I},
$$

where $\phi_{I} \geq 0$.

Using (15), the first-order condition for this problem takes the standard form

$$
\begin{gathered}
\left(1-\theta_{H H}\right)\left(\frac{P_{j t}^{H H}}{P_{t}^{H H}}\right)^{-\theta_{H H}} \frac{1}{P_{t}^{H H}}+\theta_{H H}\left(\frac{P_{j t}^{H H}}{P_{t}^{H H}}\right)^{-\theta_{H H}-1} \frac{m c_{t}^{H}}{P_{t}^{H H}} \\
-\phi_{I}\left\{\left(\frac{P_{j t}^{H H}}{P_{j t-1}^{H H}}-1\right) \frac{1}{P_{j t-1}^{H H}}\right\}+\beta \phi_{I} \mathbb{E}_{t}\left\{\frac{\lambda_{t+1}}{\lambda_{t}}\left(\frac{P_{j t+1}^{H H}}{P_{j t}^{H H}}-1\right) \frac{P_{j t+1}^{H H}}{\left(P_{j t}^{H H}\right)^{2}} \frac{Y_{t+1}^{H H}}{Y_{t}^{H H}}\right\}=0 .
\end{gathered}
$$

The law of one price implies again that the price of home intermediate goods sold on the foreign market (that is, the price of home exports), $P_{t}^{H F}$, is equal to the home price: ${ }^{7}$

$$
P_{t}^{H F}=P_{t}^{H H}
$$

As noted earlier, trade between the two countries occurs only at the level of intermediate goods. The market-clearing condition equates therefore total output of home intermediate good $j$ with world demand for that good, that is, the sum of the home and foreign demands for home good $j$ :

$$
Y_{j t}^{H I}=Y_{j t}^{H H}+Y_{j t}^{H F}
$$

with, similar to (15), $Y_{j t}^{H F}=\left(P_{j t}^{H F} / P_{t}^{H F}\right)^{-\theta_{i}} Y_{t}^{H F}$ denoting home exports. A similar condition holds for foreign production of each intermediate good $j$ :

$$
Y_{j t}^{F I}=Y_{j t}^{F F}+Y_{j t}^{F H}
$$

\footnotetext{
${ }^{7}$ From (19) and (26), the terms of trade are thus given by $P_{t}^{H F} / P_{t}^{F H}=P_{t}^{H H} / P_{t}^{F F}$. By $\log$ linearizing (18) and the equivalent definition of $P_{t}^{F}$, it can be shown that deviations in the real exchange rate are proportional to deviations in the terms of trade between the two countries.
} 
with $Y_{j t}^{F H}$ (home imports) given by $(15) .{ }^{8}$

\subsection{Capital Good Production}

The aggregate capital stock, $K_{t}^{H}=\int_{0}^{1} K_{j t}^{H} d j$, is obtained by combining gross investment, $I_{t}^{H}$, with the existing capital stock, adjusted for depreciation and adjustment costs:

$$
K_{t+1}^{H}=I_{t}^{H}+\left\{1-\delta-\frac{\Theta_{K}}{2}\left(\frac{K_{t+1}^{H}-K_{t}^{H}}{K_{t}^{H}}\right)^{2}\right\} K_{t}^{H},
$$

where $\delta \in(0,1)$ is the depreciation rate and $\Theta_{K}>0$.

Investment goods must be paid for in advance. The CG producer must therefore borrow from the bank $l_{t}^{H}=I_{t}^{H}$. The household makes its exogenous housing stock, $\bar{A}^{H}$, available without any direct charge to the CG producer, who uses it as collateral against which it borrows from the bank. Repayment is uncertain and occurs with probability $q_{t}^{H} \in(0,1)$. Expected repayment is thus $q_{t}^{H}\left(1+i_{t}^{H L}\right) I_{t}^{H}+\left(1-q_{t}^{H}\right) \kappa z_{t}^{H A} \bar{A}^{H}$, where $\kappa \in(0,1)$ is the share of the housing stock that can be effectively pledged as collateral.

Subject to (29) and $l_{t}^{H}=I_{t}^{H}$ the CG producer chooses the level of capital $K_{t+1}^{H}$ so as to maximize the value of the discounted stream of dividend payments to the household. As shown by Agénor et al. $(2014,2015)$, the solution to this problem yields ${ }^{9}$

$$
\begin{aligned}
\mathbb{E}_{t} r_{t+1}^{H K} & =q_{t}^{H}\left(1+i_{t}^{H L}\right) \mathbb{E}_{t}\left\{\left[1+\Theta_{K}\left(\frac{K_{t+1}^{H}}{K_{t}^{H}}-1\right)\right]\left(\frac{1+i_{t}^{H B}}{1+\pi_{t+1}^{H}}\right)\right\} \\
- & \mathbb{E}_{t}\left\{q_{t+1}^{H}\left(1+i_{t+1}^{H L}\right)\left\{1-\delta+\frac{\Theta_{K}}{2}\left[\left(\frac{K_{t+2}^{H}}{K_{t+1}^{H}}\right)^{2}-1\right]\right\}\right\} .
\end{aligned}
$$

\subsection{Commercial Bank}

The home bank's balance sheet is

$$
l_{t}^{H}+R R_{t}^{H}=d_{t}^{H}+l_{t}^{H B}
$$

${ }^{8}$ Note that we also have in value terms $P_{t}^{H I} Y_{t}^{H I}=P_{t}^{H H} Y_{t}^{H H}+P_{t}^{H F} Y_{t}^{H F}$, where $P_{t}^{H I}$ is the output price of intermediate goods. But given that from (26) $P_{t}^{H F}=P_{t}^{H H}$, and given (27), this condition boils down to $P_{t}^{H I}=P_{t}^{H H}$, which justfies specifying the optimization problem of the IG producer in (23) directly in terms of $P_{t}^{H H}$.

${ }^{9}$ Equation (30) boils down to the standard arbitrage condition $\mathbb{E}_{t} r_{t+1}^{H K} \simeq i_{t}^{H B}-\mathbb{E}_{t} \pi_{t+1}^{H}+\delta$ in the absence of borrowing and adjustment costs. 
where $l_{t}^{H B}$ is borrowing from the common central bank, and $R R_{t}^{H}$ required reserves, which are set as a fraction $\mu_{t}^{H} \in(0,1)$ of deposits:

$$
R R_{t}^{H}=\mu_{t}^{H} d_{t}^{H}
$$

The bank's expected real profits at the end of period $t$ (or beginning of $t+1$ ) are defined as

$$
\begin{gathered}
\mathbb{E}_{t}\left[\left(1+\pi_{t+1}^{H}\right) J_{t+1}^{H B}\right]=q_{t}^{H}\left(1+i_{t}^{H L}\right) l_{t}^{H}+\left(1-q_{t}^{H}\right) \kappa z_{t}^{H A} \bar{A}^{H} \\
+\mu_{t}^{H} d_{t}^{H}-\left(1+i_{t}^{H D}\right) d_{t}^{H}-\left(1+i_{t}^{C}\right) l_{t}^{H B}
\end{gathered}
$$

where $i_{t}^{C}$ is the marginal cost of borrowing from the common central bank, and $\mu_{t}^{H} d_{t}^{H}$ the reserve requirements held at the central bank and returned to the bank at the end of the period. The other terms in (33) are self explanatory.

The bank sets the deposit and lending rates so as to maximize expected profits:

$$
i_{t}^{H D}, i_{t}^{H L}=\arg \max \mathbb{E}_{t}\left[\left(1+\pi_{t+1}^{H}\right) J_{t+1}^{H B}\right]
$$

Solving (34) subject to (31)-(33) yields

$$
\begin{gathered}
i_{t}^{H D}=\left(1+\frac{1}{\eta_{D}}\right)^{-1}\left(1-\mu_{t}^{H}\right) i_{t}^{C}, \\
i_{t}^{H L}=\frac{1+i_{t}^{C}}{\left(1+\eta_{L}^{-1}\right) q_{t}^{H}}-1,
\end{gathered}
$$

where $\eta_{D}, \eta_{L}>0$ are interest elasticities of the supply of deposits and the demand for loans, respectively. Borrowing from the common central bank is determined residually from (31).

The repayment probability depends positively on the expected value of collateral relative to the volume of loans (as a result of a moral hazard effect), and the cyclical position of the economy (which affects incentives to repay):

$$
q_{t}^{H}=\left(\frac{\kappa \mathbb{E}_{t} z_{t+1}^{H A} \bar{A}^{H}}{l_{t}^{H}}\right)^{\varphi_{1}}\left(\frac{Y_{t}^{H}}{\tilde{Y}^{H}}\right)^{\varphi_{2}} \epsilon_{t}^{Q}, \quad \varphi_{1}, \varphi_{2}>0
$$

where $\tilde{Y}^{H}$ is the steady-state level of home final output and $\epsilon_{t}^{Q}$ a disturbance term which follows an $A R(1)$ process of the form $\epsilon_{t}^{Q}=\epsilon_{t-1}^{\rho^{Q}} \exp \left(\xi_{t}^{Q}\right)$, where $\rho^{Q} \in(0,1)$ and $\xi_{t}^{Q} \sim \mathbf{N}\left(0, \sigma_{\xi^{Q}}\right)$ 


\subsection{Government}

All income received by the union's central bank on each country's bank borrowing, $i_{t}^{C} l_{t}^{H B}$ and $i_{t}^{C} l_{t}^{F B}$, is transferred back to each national government. The government budget constraint is thus given by

$$
b_{t}^{H}=G_{t}^{H}-T_{t}^{H}+\left(1+i_{t-1}^{H B}\right) \frac{b_{t-1}^{H}}{1+\pi_{t}^{H}}-i_{t-1}^{C} \frac{l_{t-1}^{H B}}{1+\pi_{t}^{H}}
$$

where $b_{t}^{H}=b_{t}^{H H}+b_{t}^{F H}$ is the real stock of riskless one-period bonds held by home and foreign households, and $G_{t}^{H}$ real expenditure on home final goods, which represents a fraction $\psi \in(0,1)$ of home output:

$$
G_{t}^{H}=\psi Y_{t}^{H}
$$

In what follows the government in each country is assumed to keep its real stock of debt constant and to balance its budget by adjusting lump-sum taxes.

\subsection{Common Central Bank}

The common central bank operates a standing facility, which involves a perfectly elastic supply of (uncollateralized) loans to home and foreign banks, $l_{t}^{H B}$ and $l_{t}^{F B}$ respectively, at the prevailing cost of borrowing. It also supplies cash to households and firms in both countries. The balance sheet of the common central bank (measured in home prices) is thus given by

$$
l_{t}^{H B}+\left(\frac{P_{t}^{F}}{P_{t}^{H}}\right) l_{t}^{F B}=m_{t}^{H}+\left(\frac{P_{t}^{F}}{P_{t}^{H}}\right) m_{t}^{F}+R R_{t}^{H}+\left(\frac{P_{t}^{F}}{P_{t}^{H}}\right) R R_{t}^{F},
$$

where $m_{t}^{H}\left(m_{t}^{F}\right)$ is the supply of cash to the home (foreign) country, and $R R_{t}^{H}\left(R R_{t}^{F}\right)$ required reserves held by the home (foreign) country.

Changes in the supply of currency to the home country are set by the central bank to reflect only changes in home monetary conditions:

$$
m_{t}^{H}=\frac{m_{t-1}^{H}}{1+\pi_{t}^{H}}+\left(l_{t}^{H B}-\frac{l_{t-1}^{H B}}{1+\pi_{t}^{H}}\right)-\left(R R_{t}^{H}-\frac{R R_{t-1}^{H}}{1+\pi_{t}^{H}}\right),
$$

with an analogous equation for the foreign country. 
The central bank supplies liquidity elastically to the commercial bank in each country, at a price $i_{t}^{C}$, the refinance rate, which reflects both a base policy rate, $i_{t}^{R}$, and a penalty charge. In turn, the base policy rate is set on the basis of a weighted average of inflation and output in the two countries:

$$
\frac{1+i_{t}^{R}}{1+\tilde{\imath}^{R}}=\left(\frac{1+i_{t-1}^{R}}{1+\tilde{\imath}^{R}}\right)^{\chi}\left\{\left[\frac{\left(1+\pi_{t}^{H}\right)^{v / 2}\left(1+\pi_{t}^{F}\right)^{1-v / 2}}{1+\pi^{T}}\right]^{\varepsilon_{1}}\left[\left(\frac{Y_{t}^{H}}{\tilde{Y}^{H}}\right)^{v / 2}\left(\frac{Y_{t}^{F}}{\tilde{Y}^{F}}\right)^{1-v / 2}\right]^{\varepsilon_{2}}\right\}^{1-\chi}
$$

where $\tilde{\imath}^{R}$ is the steady-state value of the policy rate, $\pi_{t}^{F}=P_{t}^{F} / P_{t-1}^{F}-1, \pi^{T} \geq 0$ the union-wide inflation target, $\chi \in(0,1), \varepsilon_{1}, \varepsilon_{2}>0$ and $0<v \leq 2$ measures the weight attached to home country; when $v=1$, countries have equal weights.

The refinance rate for the home and foreign commercial banks is given by

$$
1+i_{t}^{C}=\left(1+i_{t}^{R}\right)\left(1+\theta_{t}^{C B}\right)
$$

where $\theta_{t}^{C B}$ represents a penalty rate, which is positively related to the ratio of central bank borrowing to required reserves:

$$
\theta_{t}^{C B}=\theta_{0}^{C B}\left[\left(\frac{l_{t}^{H B} / \tilde{l}^{H B}}{R R_{t}^{H} / \widetilde{R R}^{H}}\right)^{v / 2}\left(\frac{l_{t}^{F B} / \tilde{l}^{F B}}{R R_{t}^{F} / \widetilde{R R}}\right)^{1-v / 2}\right]^{\chi^{C B}}
$$

with $\theta_{0}^{C B}, \chi^{C B}>0$. Thus, the penalty rate increases with the amount borrowed and falls with the amount of reserves held at the central bank, which act as (implicit) collateral. By implication, the penalty rate is constant at $\theta_{0}^{C B}$ in the steady state. This specification provides a simple and intuitive way to introduce imperfect substitutability between deposits and central bank borrowing - a necessary condition for reserve requirements to operate in a countercyclical fashion. ${ }^{10}$

The production structure and the main real and financial flows between agents are summarized in Figure 1.

\section{Equilibrium and Steady State}

In a symmetric equilibrium, all intermediate-good firms, at home and abroad, produce the same output and prices are the same across firms. Thus, the market-clearing

\footnotetext{
${ }^{10}$ See Agénor et al. (2015) for a detailed discussion. In a model with multiple banks and an interbank market, the penalty rate could be defined as a premium that banks charge for borrowing from each other and could be related to the ratio of the amount borrowed over each bank's core funding or equity capital.
} 
conditions (27) and (28) for good $j$ also imply that total output of home and foreign intermediate goods be equal to world demand for those goods:

$$
Y_{t}^{H I}=Y_{t}^{H H}+Y_{t}^{H F}, \quad Y_{t}^{F I}=Y_{t}^{F F}+Y_{t}^{F H} .
$$

Equilibrium in the market for final goods in each country requires that output be equal to domestic absorption, inclusive of price adjustment costs:

$$
\begin{gathered}
Y_{t}^{H}=C_{t}^{H}+G_{t}^{H}+I_{t}^{H}+\frac{\phi_{I}}{2}\left(\frac{P_{t}^{H H}}{P_{t-1}^{H H}}-1\right)^{2}\left(\frac{P_{t}^{H H}}{P_{t}}\right) Y_{t}^{H I} \\
Y_{t}^{F}=C_{t}^{F}+G_{t}^{F}+I_{t}^{F}+\frac{\phi_{I}}{2}\left(\frac{P_{t}^{F F}}{P_{t-1}^{F F}}-1\right)^{2}\left(\frac{P_{t}^{F F}}{P_{t}^{F}}\right) Y_{t}^{F I},
\end{gathered}
$$

Bank loans are made in the form of cash. The equilibrium condition of the home currency market is thus

$$
m_{t}^{H}=m_{t}^{H P}+l_{t}^{H}
$$

and analogously for the foreign country.

In equilibrium, net trade in government bonds (or, equivalently, the world net supply of bonds) must be zero, so that

$$
b_{t}^{H H}+b_{t}^{F H}=0, \quad b_{t}^{F F}+b_{t}^{H F}=0 .
$$

Analogously, in a two-country world current account excesses and deficits must be zero:

$$
C A_{t}^{H}+C A_{t}^{F}=0
$$

with the home country's current account defined as

$$
C A_{t}^{H}=P_{t}^{H H} Y_{t}^{H F}-P_{t}^{F F} Y_{t}^{F H}+i_{t-1}^{F} P_{t-1}^{H} b_{t-1}^{H F}-i_{t-1}^{H} P_{t-1}^{H} b_{t-1}^{F H},
$$

where $Y_{t}^{H F}$, exports of intermediate goods by the home country, correspond to the foreign country's imports, $Y_{t}^{F H}$, home imports, correspond to the foreign country's exports of intermediates, and $i_{t}^{H}$ (symmetrically to (4) and (5)) is the premium-adjusted home bond rate, defined as

$$
1+i_{t}^{H}=\left(1+i_{t}^{H B}\right)\left(1+\theta_{t}^{F H}\right),
$$


where $\theta_{t}^{F H}$ is the spread faced by foreign households, defined as

$$
\theta_{t}^{F H}=-\frac{\theta_{0}^{B}}{2} b_{t}^{F H}
$$

with $\theta_{0}^{F H}>0 .{ }^{11}$

The steady-state solution of the model is described in Appendix A. Its key features are similar to those described in Agénor et al. (2014, 2015) for an individual country, so we refer to those papers for a detailed discussion. In brief, the home repayment probability is $\tilde{q}^{H}=\left(\kappa \tilde{z}^{H A} \bar{A}^{H} / \tilde{l}^{H}\right)^{\varphi_{1}}$, whereas home interest rates are given by $\tilde{\imath}^{H B}=$ $\beta^{-1}-1, \tilde{\imath}^{H B}=\tilde{\imath}^{C}$ (which implies that the bank has no incentives to borrow from the central bank to purchase bonds $), \tilde{\imath}^{H D}=\left(1+\eta_{D}^{-1}\right)^{-1}\left(1-\tilde{\mu}^{H}\right) \tilde{\imath}^{C}$, and $\tilde{\imath}^{H L}=\beta^{-1} /(1+$ $\left.\eta_{L}^{-1}\right) \tilde{q}^{H}-1$. The cost of borrowing from the common central bank is thus $1+\tilde{\imath}^{C}=$ $\left(1+\tilde{\imath}^{R}\right)\left(1+\tilde{\theta}_{0}^{C B}\right)>1+\tilde{\imath}^{R}$. From these equations it can be shown that $\tilde{\imath}^{H D}<\tilde{\imath}^{C}$ and, because $\eta_{L}<0, \tilde{q}^{H}\left(1+\tilde{\imath}^{H L}\right)>1+\tilde{\imath}^{C}$, which ensures that $\tilde{\imath}^{H L}>\tilde{\imath}^{C}$ and that the bank always has an incentive to borrow from the central bank. They also yield $\tilde{q}^{H}\left(1+\tilde{\imath}^{H L}\right)>1+\tilde{\imath}^{H B}$, which implies that in equilibrium the bank has no incentive to hold government bonds. Finally, the steady-state value of the stock of foreign bonds held by the representative home household is $\tilde{b}^{H F}=\left(\tilde{\imath}^{F B}-\tilde{\imath}^{H B}\right) / \theta_{0}^{B}\left(1+\tilde{\imath}^{F B}\right)$, which is positive as long as the foreign (risk-free) bond rate exceeds the home bond rate.

\section{Parameterization}

To study the properties of the model we parameterize it using standard values used in the literature on small open-economy and two-country models - especially those focusing on the euro area, for which a number of recent papers provide parameter values estimated with Bayesian techniques. In addition, for some of the parameters that are deemed critical from the perspective of this study, sensitivity analysis is reported later on. In the benchmark parameterization, we assume that the two countries are perfectly symmetric.

\footnotetext{
${ }^{11}$ Consolidating all the budget constraints also yields (recalling that the nominal exchange rate is normalized to unity) $C A_{t}^{H}=\left(P_{t}^{H} b_{t}^{H F}-P_{t-1}^{H} b_{t-1}^{H F}\right)-\left(P_{t}^{H} b_{t}^{F H}-P_{t-1}^{H} b_{t-1}^{F H}\right)$, where changes in holdings of the home country's foreign bonds correspond to a capital outflow for the home country (or an inflow for the foreign country), whereas changes in holdings of the foreign country's home bonds, correspond to a capital inflow for the home country.
} 
The discount factor $\beta$ is set at 0.99 , which gives a steady-state annualized real interest rate of about 4.1 percent. The intertemporal elasticity of substitution is 0.5 , in line with the empirical evidence discussed by Braun and Nakajima (2012) for instance and the calibrated value used by Brzoza-Brzezina et al. (2015) for their core-periphery model of the euro area (see also Thimme (2017)). The preference parameter for leisure, $\eta_{N}$, is set at 10 , to ensure that in the steady state households devote one third of their time endowment to market activity, a fairly common benchmark in the literature (see Corsetti et al. (2014), Christoffel and Schabert (2015), and Poutineau and Vermandel (2015) for instance). The parameter for composite monetary assets, $\eta_{x}$, is set at a low value, 0.02 , to capture the common assumption in the literature that their weight in household preferences is negligible (see for instance Coenen et al. (2009) and Christoffel and Schabert (2015)). The same value is used for the housing preference parameter, $\eta_{A}$. The share parameter in the index of money holdings, $\nu$, which corresponds to the relative share of cash in narrow money, is set at 0.2 to capture a significantly higher use of deposits in transactions. The cost parameter related to foreign (home) bond holdings by home (foreign) households, $\theta_{0}^{B}$, is set at 0.1 . This value is consistent with a relatively high, albeit imperfect, degree of capital mobility.

The distribution parameter between home and imported intermediate goods in the production of the final good, $\Lambda_{I}$, is set at 0.7 , to capture the case of a country where imports are initially about a third of GDP, as in Tomura (2010) for instance. The same value is used for the foreign country. The elasticity of substitution between baskets of domestic and imported composite intermediate goods, $\eta$, is set at 1.5 , a fairly standard value, which implies that these goods are substitutes in the production of the final good. The elasticities of substitution between home intermediate goods among themselves, $\theta_{H H}$, and imported goods among themselves, $\theta_{F F}$, are both set equal to 10 . This is the same value used by Quint and Rabanal (2014) for instance.

The share of capital in domestic output of intermediate goods, $\alpha$, is set at 0.35 , a fairly standard value. The adjustment cost parameter for prices of domestic intermediate goods, $\phi_{D}$, is set at 74.5 to capture a relatively high degree of nominal price stickiness. This value is very close to the average value initially estimated by Ireland (2001, Table 3) and implies a Calvo-type probability of not adjusting prices of approx- 
imately 0.71 percent per period, or equivalently an average period of price fixity of about 3.5 quarters. These figures are consistent with the point estimates of Quint and Rabanal (2014, Table 2) and Christoffel and Schabert (2015, Table 2) for the euro area. They are also in the range of values estimated by Gerali et al. (2010) and Darracq Pariès et al. (2011). The capital depreciation rate, $\delta$, is set at a quarterly rate of 0.025 , which is in the span of values typically used in the literature (see for instance Gerali et al. (2010), Kolasa and Lombardo (2014) and Mendicino and Punzi (2014)). The adjustment cost incurred by the CG producer for transforming investment into capital, $\Theta_{K}$, is set at 14 , in order to match the fact that the standard deviation of the cyclical component of investment is 3 to 4 times more volatile as GDP in the euro area. This value is also close to the upper bound estimated by Gerali et al. (2010, Table 2A) for the euro zone.

Regarding the commercial bank, the effective collateral-loan ratio, $\kappa$, is set at 0.2 , to capture the relatively high costs associated with debt enforcement procedures, as documented by Djankov et al. (2008). The elasticity of the repayment probability is set at $\varphi_{1}=0.05$ initially with respect to the effective collateral-loan ratio and at $\varphi_{2}=0.2$ with respect to deviations in output from its steady state. As discussed later, we perform sensitivity analysis with respect to $\varphi_{2}$, to assess the role of credit market imperfections.

Regarding the common central bank, the required reserve ratio $\mu^{R}$ is set at 0.08 ; this value is higher than those reported for the euro area (see Christoffel and Schabert (2015)) but they are consistent with data for other high-income countries (see Cerutti et al. (2017)). The degree of persistence in the central bank's policy response, $\chi$, is set at 0.8 , whereas the responses of the base policy rate to inflation and output deviations, $\varepsilon_{1}$ and $\varepsilon_{2}$, are set at 1.6 and 0.15 , respectively. These values represent averages of the estimates reported by Brzoza-Brzezina et al. (2015, Table 1), Quint and Rabanal (2014, Table 2), and Christoffel and Schabert (2015, Table 2) for the euro area.

The elasticity of the penalty rate to the bank borrowing-required reserves ratio, $\chi^{C B}$, is set to 1.1 , to capture a convex cost and imperfect substitutability between central bank liquidity and deposits. The scale parameter $\theta_{0}^{C B}$ is set to a low value of 0.0007 , to ensure that the refinance rate is (almost) identical to the policy rate in the 
steady state. The share of noninterest government spending in final output, $\psi$, is set at 0.18, as in Christoffel and Schabert (2015). This value is also close to the value of 0.2 used by Corsetti et al. (2014) for instance and several other contributions. The autocorrelation coefficients of the productivity and repayment probability shocks, $\rho^{Y}$ and $\rho^{Q}$, are set at 0.8 and 0.57 , respectively. The latter value is the same as the value estimated by Alpanda and Aysun (2014) for their spread shock.

Parameter values are exactly identical for the two countries initially and are summarized in Table 1.

\section{Experiments}

To illustrate the properties of the model, we briefly examine the international transmission of two types of real and financial shocks occurring in the home country: a positive productivity shock and an adverse financial shock, captured by a negative shock to the repayment probability. The latter is similar to a negative shock to the demand for housing services in (1), or equivalently (given constant supply) a shock to real house prices, which affects collateral values and thus the risk of default. In both cases we assume initially that countries are of the same size (so that $v=1$ ) and consider later the case of unequal proportions.

\subsection{Productivity Shock}

The results of a positive home productivity shock are illustrated in Figure 2. The higher level of home output raises the repayment probability and reduces the domestic loan rate, which stimulates investment and aggregate demand. The fall in marginal cost lowers inflation, which in turn induces the common central bank to set a lower policy rate despite the fact that higher cyclical output at home operates in the opposite direction. The deposit rate therefore falls, and so does the bond rate. The drop in nominal market interest rates exceeds the fall in the (one-period ahead) inflation rate, thereby reducing the real bond rate and inducing households to spend more and save less today. The increase in consumption is associated with higher demand for housing services, thereby raising house prices. In turn, higher house prices increase 
collateral values and further contributes to the initial increase in the repayment probability and the drop in the loan rate, magnifying in the process the initial increase in home investment and output.

The shock is transmitted to the foreign country through trade, financial, and monetary policy channels. The increase in home output leads to higher demand for both home and imported intermediate inputs, which stimulates output abroad and generates first-round effects that are qualitatively similar to (although smaller in magnitude than) those described earlier for the home economy. The fall in domestic interest rates leads to higher demand for foreign assets and a capital inflow in the foreign economy, which tends to lower the bond rate there as well. Finally, the initial drop in home inflation leads (as noted earlier) to a drop in the base policy interest rate set by the common central bank, which further contributes to a fall in the loan rate in the foreign economy. This monetary policy channel is a key feature of currency unions. ${ }^{12}$

\subsection{Financial Shock}

The results of a negative shock to the repayment probability in the home country are illustrated in Figure 3. The direct effect of this shock is to raise the loan rate and to reduce investment at home. This leads to a contraction in aggregate demand and to lower inflation. Because the initial impact is also a reduction in average inflation, the central bank lowers the policy rate, which tends to reduce market interest rates at home and abroad. ${ }^{13}$ In the home country the (expected) real bond rate falls initially, thereby raising consumption and house prices; in the foreign country, by contrast, the opposite occurs - capital inflows are associated with a higher real bond rate, thereby reducing

\footnotetext{
${ }^{12}$ Because inflation falls more in the home country, and because the central bank reduces the common policy rate on the basis of the behavior of average inflation, the real interest rate falls by more in the home country than in the foreign country. In the absence of a currency union, the home central bank would have cut its policy rate by more than the common central bank (whose decisions are based on country averages) does. The policy channel helps therefore to mitigate domestic macroeconomic fluctuations.

${ }^{13}$ In the foreign country, the drop in output tends to lower the repayment probability, which should normally leads to a higher lending rate; however, this effect is dominated by the drop in the refinance rate. Note also that investment abroad also falls, despite the reduction in the loan rate, as a result of the expected increase in inflation.
} 
current consumption and house prices there. ${ }^{14}$ However, the increase in consumption at home is relatively small compared to the drop in investment, so the net effect on aggregate demand is negative. In addition to the monetary policy channel, the cross-border propagation of the home country shock occurs again through trade in intermediate goods, which is driven by changes in the relative price of home and foreign final goods.

The positive co-movements among countries in output, inflation and investment associated with both shocks are consistent with the predictions of a large number of econometric and simulation studies that have studied the cross-border effects of these shocks in open economies. We have assumed, however, that countercyclical policy is implemented only through the setting of policy rates by the common central bank; we now turn to the case where macroprudential policy also responds endogenously under alternative institutional mandates.

\section{Optimal Simple Macroprudential Rules}

As discussed in the introduction, the key issue that we want to address in this paper is whether, in a currency union, financial stability is better achieved by conducting macroprudential policy (in the form of countercyclical reserve requirements) at the level of the union, instead of its individual members. To do so we compare outcomes under two alternative mandates, under the assumption that monetary policy continues to be conducted by the common central bank. The first is the decentralized (or autonomous) regime, where countries pursue independent policies and set reserve requirements unilaterally. In a situation akin to a Nash bargaining game, each regulator sets its own optimal macroprudential rule, taking as given the behavior of the other regulator. A Nash equilibrium in this setting is a combination of home and foreign required reserve ratios - or, more accurately, response parameters in required reserve rules, as shown later-for which neither country can unilaterally deviate from and generate some gain by doing so.

\footnotetext{
${ }^{14}$ The effect on foreign consumption is however significantly smaller, which explains why the drop in foreign output is much weaker.
} 
The second is the centralized (or cooperative) regime where either a single or separate required reserve ratios are set for both countries by the common central bank. In both cases, we consider a simple policy rule whereby changes in the required reserve ratio are related to an operational target for financial (in)stability, deviations in the ratio of bank loans to final output. ${ }^{15}$ The focus on that variable is consistent with the large body of evidence suggesting that fluctuations in credit have often been associated with financial crises (see for instance Aikman et al. (2015) and Taylor (2015)).

Specifically, in the first regime, changes in the required reserve ratio in each country $i=H, F$ are driven by: ${ }^{16}$

$$
\frac{1+\mu_{t}^{i}}{1+\tilde{\mu}^{i}}=\left(\frac{1+\mu_{t-1}^{i}}{1+\tilde{\mu}^{i}}\right)^{\chi_{1}}\left\{\left(\frac{l_{t}^{i} / Y_{t}^{i}}{\tilde{l}^{i} / \tilde{Y}^{i}}\right)^{\chi_{2}^{D, i}}\right\}^{1-\chi_{1}},
$$

where $\chi_{1} \in(0,1)$ is a persistence parameter and $\chi_{2}^{D, i}>0$ is the response parameter to deviations in the credit-to-output ratio. ${ }^{17}$ In this case, the financial regulator in each country determines the optimal value of $\chi_{2}^{D, i}$ so as to minimize its loss function $\mathcal{L}_{t}^{D, i}$ or its own measure of financial risks, defined in terms of the volatility of the credit-to-GDP ratio:

$$
\min _{\chi_{2}^{D, i}} \mathcal{L}_{t}^{D, i}=\operatorname{var}\left(\frac{l_{t}^{i}}{Y_{t}^{i}}\right) .
$$

In the second regime, and assuming separate instrument setting for each member, the common policy responds to a geometric average of country-specific credit-to-output ratios:

$$
\frac{1+\mu_{t}^{i}}{1+\tilde{\mu}^{i}}=\left(\frac{1+\mu_{t-1}^{i}}{1+\tilde{\mu}^{i}}\right)^{\chi_{1}}\left\{\left[\left(\frac{l_{t}^{H} / Y_{t}^{H}}{\tilde{l}^{H} / \tilde{Y}^{H}}\right)^{\chi_{2}^{C, H}}\right]^{v / 2}\left[\left(\frac{l_{t}^{F} / Y_{t}^{F}}{\tilde{l}^{F} / \tilde{Y}^{F}}\right)^{\chi_{2}^{C, F}}\right]^{1-v / 2}\right\}^{1-\chi_{1}}
$$

The common central bank sets now $\chi_{2}^{C, H}$ and $\chi_{2}^{C, F}$, but this time to minimize the union-wide loss function or a common measure of financial risks, defined in terms of a weighted average of individual country loss functions:

$$
\min _{\chi_{2}^{C, H}, \chi_{2}^{C, F}} \mathcal{L}_{t}^{C}=\frac{v}{2} \mathcal{L}_{t}^{C, H}+\left(1-\frac{v}{2}\right) \mathcal{L}_{t}^{C, F}
$$

\footnotetext{
${ }^{15}$ See Agénor et al. (2015) for a more detailed discussion of the rationale for this type of rule.

${ }^{16}$ As can be inferred from (54), as well as (56) and (58), the values of the optimal response parameters do not affect the steady-state level of the required reserve ratio, only its cyclical properties.

${ }^{17}$ Throughout this discussion, the persistence parameter $\chi_{1}$ is kept constant.
} 
where $\mathcal{L}_{t}^{C, i}$ is defined in a way similar to $(55)$.

Alternatively, we also consider the case where the common regulator follows a onesize-fits-all policy and sets a uniform, union-wide required reserve ratio:

$$
\frac{1+\mu_{t}}{1+\tilde{\mu}}=\left(\frac{1+\mu_{t-1}}{1+\tilde{\mu}}\right)^{\chi_{1}}\left\{\left[\left(\frac{l_{t}^{H} / Y_{t}^{H}}{\tilde{l}^{H} / \tilde{Y}^{H}}\right)^{v / 2}\left(\frac{l_{t}^{F} / Y_{t}^{F}}{\tilde{l}^{F} / \tilde{Y}^{F}}\right)^{1-v / 2}\right]_{2}^{\chi_{2}}\right\}^{1-\chi_{1}}
$$

and therefore chooses $\chi_{2}^{C}$ so that

$$
\min _{\chi_{2}^{C}} \mathcal{L}_{t}^{C}=\frac{v}{2} \mathcal{L}_{t}^{C, H}+\left(1-\frac{v}{2}\right) \mathcal{L}_{t}^{C, F}
$$

To measure the gains - or lack thereof - from coordination, two issues must be addressed: a) whether, from the perspective of each individual member, own-country policy loss in the centralized regime (based on the common optimal rule) is lower than in the decentralized regime (based on each country's own optimal rule); and $b$ ) whether, from the perspective of the union as a whole, union-wide policy loss in the centralized regime is smaller than the aggregate policy loss in the decentralized regime, calculated as a weighted average $(v / 2,1-v / 2)$ of each country's policy loss under autonomy. A smaller policy loss for each country under $a$ ) is a sufficient, but not necessary, condition for a smaller policy loss under $b$ ). The outcome in that second case also depends on the magnitude of the individual country gains (or losses) in the decentralized regime and the relative weight of each member country, as measured by $v$, in the common loss function.

To calculate the policy gain under $a$ ), we take the relative difference between the value of each country's loss function, evaluated at either the separate optimal values $\hat{\chi}_{2}^{C, H}$ and $\hat{\chi}_{2}^{C, F}$ or the common optimal response parameter $\hat{\chi}_{2}^{C}$ (solved for in both cases by the common regulator minimizing the union-wide loss function (57) or (59)), that is, $\hat{\mathcal{L}}_{t}^{C, i}$, and the minimized value of each country's loss function at the optimal own response parameter $\hat{\chi}_{2}^{D, i}$ (solved for independently by each national regulator based on $(55)), \hat{\mathcal{L}}_{t}^{D, i}$. The sign of the two measures $\hat{\mathcal{L}}_{t}^{C, i}-\hat{\mathcal{L}}_{t}^{D, i}$ allows us therefore to assess the gain or loss associated with macroprudential policy coordination, from the perspective of each member separately.

To calculate the gains under $b$ ), we take the relative difference between the minimized value of the union-wide loss function at the separate optimal values $\hat{\chi}_{2}^{C, H}$ and 
$\hat{\chi}_{2}^{C, F}$ or the common optimal response parameter $\hat{\chi}_{2}^{C}, \hat{\mathcal{L}}_{t}^{C}$, and the weighted average of the minimized values of each country's loss function at the optimal own response parameter $\hat{\chi}_{2}^{D, i}$, solved for independently by each country in the decentralized regime, defined as $\hat{\mathcal{L}}_{t}^{D}=v / 2 \hat{\mathcal{L}}_{t}^{D, H}+(1-v / 2) \hat{\mathcal{L}}_{t}^{D, F}$. The sign of $\hat{\mathcal{L}}_{t}^{C}-\hat{\mathcal{L}}_{t}^{D}$ determines again the gains (or losses) from coordination, but this time from the perspective of the union as a whole, rather than a particular member.

Figures 4 and 5, and the first two columns of Table 2, show the results for the productivity and financial shocks discussed earlier. In all cases, we set again $v=1$ and the degree of persistence in the individual country and common rules, $\chi_{1}$, to a fairly low value, $0.1 .^{18}$ We use a grid step of 1.5 (0.5) for the response parameter to the credit-to-output ratio for the productivity (financial) shock. Figure 4 corresponds to the uniform instrument case under cooperation; the curve in each panel shows a relative measure of the value of the policy loss function for both members, calculated by dividing the loss when $\chi_{2}>0$, with the policy loss when $\chi_{2}=0$, that is, when there is no countercyclical rule in operation. Based on the methodology explained earlier, the optimal values of $\chi_{2}, 15$ and 5.5, are those that minimize the common loss function (59). Figure 5 corresponds to the case where the common regulator sets the response parameters separately for the two countries; for each shock, there is therefore a pair of values for $\chi_{2}-18,3$ for the productivity shock and 6,1 for the financial shock, which minimize (57). For comparative purposes, Table 2 also reports the individual country and union-wide loss functions when $\chi_{2}=0$, that is, in the absence of countercyclical regulatory response. For convenience, we also report the gains from coordination in relative terms, that is, in proportion of outcomes under decentralization.

The results show first that the (relative) policy loss function has a U-shape form, in both the centralized and decentralized regimes. The intuition is as follows. Initially, as the policy is implemented, volatility begins to fall, because it stabilizes credit, investment and aggregate demand. However, as the policy becomes more aggressive, the more volatile market interest rates become; in turn, the volatility in interest rates induces more volatility in investment and output, and therefore financial volatility - so much so that it eventually dominates the initial gains. Thus, there exists an optimal

\footnotetext{
${ }^{18}$ Results with an alternative value of 0.8 do not affect qualitatively the results.
} 
value for the response parameter to the credit-to-output ratio for the home country regulator (decentralized regime) and for the common financial regulator (centralized regime). However, in the decentralized regime, the optimal response involves a corner solution for the foreign country — with asymmetric shocks originating in the home country only, it is optimal for the foreign regulator not to respond through countercyclical adjustment in its required reserve ratio.

Second, the results in Table 2 show that although the gains from coordination are positive at the union level and for the foreign country for both types of shocks, this is the case for the home country only when the financial shock occurs. For the union as a whole, the gain is of the order of 3 (1.1) percentage points for the productivity (financial) shock when setting a uniform instrument, and 4.4 (1.9) percentage points for the productivity (financial) shock when setting separate instruments. ${ }^{19}$ Intuitively, the common regulator internalizes the effects of credit fluctuations (occurring through spillovers to the foreign country and spillbacks to the home country) in both members by pursing a more aggressive policy and is therefore able to generate a superior outcome for the union as a whole - particularly so when separate macroprudential rules are set for the the two members. Indeed, a comparison of the optimal policies suggests that a common macroprudential policy in a union where members are structurally identical but facing asymmetric financial shocks implies a more uniform response than under the decentralized regime: instead of response parameter pairs of 27,0 and 7, 0 to the productivity and financial shocks (implying, as noted earlier, no response by the foreign country), the corresponding responses are 15 and 5.5 under the one-size-fitsall policy and 18, 3 and 6, 1 for separate instruments, respectively. Thus, under a centralized regime, the home country's response is less aggressive, and the foreign country's response more aggressive. The broader response at the union level translates into a coordination gain. In fact, under coordination the foreign country benefits a lot more from coordination than the home country - particularly so when the shock is real

\footnotetext{
${ }^{19} \mathrm{By}$ implication, as can also be inferred from Table 2, optimal countercyclical macroprudential regulation always lead to a lower union-wide policy loss, that is, lower financial volatility compared to the case where required reserve ratios are kept constant across union members in response to shocksregardless of whether policies are centralized or decentralized. This result also holds for subsequent experiments reported in Tables 3 to 6 .
} 
and when instruments are set separately by the common regulator.

However, the results also indicate that the home country benefits from coordination only when a financial shock occurs - regardless of whether the central regulator sets its policy instrument uniformly or separately for each member. When a productivity shock occurs, it is transmitted directly across borders through changes in imports and exports of intermediate goods; its effect on the foreign credit-to-output ratio is fairly muted. Consequently, the response by the common regulator, which involves a weaker response than the home regulator, implies that volatility of that ratio is actually higher under coordination. $^{20}$ Put differently, the home country would be better off acting alone; short of a politically-motivated decision to join a common macroprudential policy, its willingness to cooperate can be secured only if it involves a side payment or a transfer from the union member who benefits from it.

In summary, there are two major implications of these results. The first is that, when countries in a currency union are faced with asymmetric shocks, macroprudential policy coordination is beneficial to all members (and, by implication, the union) only when shocks are financial in nature; for real shocks, the country of origin may be worse off- even when the union as a whole benefits from a centralized policy regime. In a sense, this corroborates a key result obtained elsewhere in the literature, which suggests that macroprudential policy is effective mainly when it responds to financial shocks. However, in such conditions, enforcing a cooperative agreement requires either maintaining adequate transfer incentives between winners and losers, or imposing a binding political commitment on all union members. The second implication is that although a one-size-fits-all macroprudential policy can generate benefits from coordination, especially when shocks are financial in nature, setting instruments separately - assuming that this policy is feasible in real time - generates superior outcomes.

These results differ from those of the earlier empirical literature on monetary policy cooperation, in which under a high degree of capital mobility and flexible exchange rates the gains from international policy coordination are shown to be quantitatively small

\footnotetext{
${ }^{20}$ By contrast, when a financial shock occurs, given its direct effect on the loan rate and the creditto-output ratio, both countries benefit from a coordinated countercyclical response; cooperation is thus Pareto improving in that case.
} 
if policy is optimal in each country (see Taylor (2013) and Banerjee et al. (2016)). But they are consistent with the results in Fujiwara and Teranishi (2017), who provide support (in a two-country model with flexible prices and monopolistic banking) to the idea that monetary policy cooperation can be welfare improving in the presence of financial frictions taking the form of staggered loan contracts and sticky loan rates, and more directly related to the results in Agénor et al. (2017) regarding tax-like macroprudential regulation in a core-periphery setting with financial frictions.

\section{Sensitivity Analysis}

To assess the robustness of our results with respect to the gains from coordination, we perform sensitivity analysis with respect to the following features: the measurement of financial stability, the role of output stability and the degree of asymmetry in policy preferences between national regulators and the common regulator, the degree of financial integration, heterogeneity in credit market imperfections across countries - a potentially important consideration when assessing the implications of asymmetric financial shocks in currency unions, as discussed by Agénor and Aizenman (2011) correlated shocks across countries, and asymmetric country size.

\subsection{House Prices and Financial Stability}

In the foregoing analysis financial stability was measured in terms of the volatility of the credit-to-output ratio only, in line with the robust empirical evidence on its predictive capacity as an indicator for the build-up of financial vulnerabilities. In addition some contributions, such as Anundsen et al. (2014), have also identified booms in house prices as a cause of financial fragility and financial crises - especially in an environment when borrowers are able to concomitantly lever up the collateral value of their assets.

Accordingly, we extend our analysis by assuming that financial regulators evaluate financial stability by a weighted average of the volatility of both the credit-to-output ratio and real house prices; equation (55) takes now the form

$$
\mathcal{L}_{t}^{D, i}=\varkappa \operatorname{var}\left(\frac{l_{t}^{i}}{Y_{t}^{i}}\right)+(1-\varkappa) \operatorname{var}\left(z_{t}^{i A}\right) . \quad i=H, F
$$


where $\varkappa \in(0,1)$. To account for the evidence that once the magnitude of credit expansion is taken into account, the occurrence or the magnitude of booms in asset prices do not contribute significantly to predicting financial crises, we set $\varkappa=0.85$.

The results are reported in the last two columns of Table 2. Although the magnitude of the gains are by and large smaller than in the base experiment (mainly because the foreign country gains less under coordination), they remain consistent with them. In particular, when a productivity shock occurs the home country achieves once again a policy loss under coordination, relative to noncooperation-regardless of the way the policy instrument is set by the common regulator.

\subsection{Output Stability and Asymmetric Policy Preferences}

As noted in the introduction, an ongoing debate focuses on whether in currency unions, where countries cannot conduct independent exchange rate and monetary policies (and with fiscal policy increasingly constrained by budget rules), macroprudential policies should not be used more actively to achieve output stability. ${ }^{21}$ To the extent indeed that these policies may alter the monetary transmission mechanism (through their impact on credit flows and market interest rates) they may also help to achieve price stability and dampen output fluctuations.

We address this issue by modifying the policy loss function of national regulators (55) to

$$
\mathcal{L}_{t}^{D, i}=\varkappa \operatorname{var}\left(\frac{l_{t}^{i}}{Y_{t}^{i}}\right)+(1-\varkappa) \operatorname{var}\left(\frac{Y_{t}^{i}}{\tilde{Y}^{i}}\right), \quad i=H, F
$$

which implies that the loss function of the common regulator becomes, setting $v=1$,

$$
\mathcal{L}_{t}^{C}=0.5\left\{\varkappa^{C}\left[\operatorname{var}\left(\frac{l_{t}^{H}}{Y_{t}^{H}}\right)+\operatorname{var}\left(\frac{l_{t}^{F}}{Y_{t}^{F}}\right)\right]+\left(1-\varkappa^{C}\right)\left[\operatorname{var}\left(\frac{Y_{t}^{H}}{\tilde{Y}^{H}}\right)+\operatorname{var}\left(\frac{Y_{t}^{F}}{\tilde{Y}^{F}}\right)\right]\right\},
$$

where $\varkappa, \varkappa^{C} \in(0,1)$. We consider two alternative cases. In the first case, which we refer to as symmetric policy preferences, both national regulators and the common regulator attach the same (low) weight to output stability; in the experiments, we use $\varkappa=\varkappa^{C}=0.9$. In the second, referred to as asymmetric policy preferences, we assume that the common regulator attaches a higher weight to financial stability than

\footnotetext{
${ }^{21}$ See for instance Gelain and Ilbas (2014) and Sergeyev (2016).
} 
national regulators; in a sense, the common regulator internalizes more than its national counterparts the fact that spillovers create financial risks. In that scenario, we use $\varkappa=0.9$ and $\varkappa^{C}=0.95 .^{22}$

The results are reported in Table 3. They show first that, compared to the base results reported in the first two columns of Table 2, the gains from coordination remain significant, albeit smaller under symmetric policy preferences for output stability. The fact that the home country benefits less under a productivity shock also holds. By contrast, with asymmetric policy preferences, the gains from coordination at the union level are significantly larger than in the base case or the case of symmetric preferences, regardless of how the instrument is set by the common regulator and the type of shocks hitting the home country. In addition, the gain is larger for both the home country (under both shocks) and the foreign country (under the financial shock). Intuitively, by attaching a greater weight to financial stability than national regulators, common policies generate a larger gain from coordination.

\subsection{Financial Integration}

The impact of the degree of financial integration on the gains from coordination can be assessed by considering a reduction in the coefficient, $\theta_{0}^{B}$, which (as shown earlier) helps to parameterize the degree of capital mobility. To analyze the effects of increased integration, we set $\theta_{0}^{B}$ to a smaller value of 0.05 , instead of 0.1 .

The results of this experiment are reported in the first two columns of Table 4. Qualitatively, they are similar to those reported in the base case experiment - except that now, the home country also gains from the productivity shock when the required reserve ratio is set uniformly across countries. This essentially reflects the fact that the cross-border transmission of this shock through the financial channel, and its spillback effect on the domestic economy, are now stronger. More importantly, in quantitative terms the gains from coordination are significantly larger than those reported in Table

\footnotetext{
${ }^{22}$ A conceptually similar approach to our second case is pursued in Bodenstein et al. (2014), although their focus is on welfare maximization. Breaking the first two terms and the third in their equation (65), and multiplying the third by $1-\beta$ to keep the limit finite, yields the sum of the household utility function minus a coefficient $\mu_{m p r}$ times the unconditional variance of the interest spread - whose volatility is directly linked to credit volatility. Thus, in their setting the policymaker is concerned not only with maximizing utility but also with minimizing financial volatility.
} 
2 - both at the level of the individual member countries and the union as a whole. With greater financial integration, changes in domestic and foreign interest rates become more closely correlated. This implies that shocks in the home country are transmitted to a greater extent to the foreign country, implying therefore larger spillovers and greater cross-border synchronization, which are internalized by the common regulator. This magnifies the benefits of cross-border coordination of macroprudential policies in a currency union. These results are consistent with those of Sutherland (2004) with respect to the gains from monetary policy coordination associated with greater financially integration, although our focus is on credit market imperfections and financial stability rather than risk sharing.

\subsection{Credit Market Imperfections}

In the foregoing analysis it was assumed that members of the union are symmetric in all respects. An issue worth exploring is whether the gains from coordination tend to increase or fall when there is heterogeneity in credit market imperfections across countries. ${ }^{23}$ In the present model, the magnitude of these imperfections is captured through different parameters: the share of collateral that borrowers must pledge to secure loans, $\kappa$; and the response parameters of the repayment probability (or, equivalently, the inverse of the risk premium charged to borrowers) with respect to the collateral-loan ratio and cyclical output, $\varphi_{1}$ and $\varphi_{2}$, respectively. ${ }^{24}$ We focus in what follows on changes in $\varphi_{2}$ and consider two experiments.

First, we consider the case where, compared to the original experiment, the parameter $\varphi_{2}$ takes a higher value (0.25 instead of 0.2) for both countries. Results are reported in the last two columns of Table 4. They show first that, in contrast to the base experiment, both the home and foreign members benefit from coordination when instruments are set separately. Even though, in that case, the foreign country gains

\footnotetext{
${ }^{23}$ Gilchrist (2004) and Faia (2007) were among the first to draw attention to the role of differences in financial structures and financial frictions for the international propagation of shocks in open economies. Neither contribution, however, considers the benefits of cross-border policy coordination in mitigating the impact of these shocks.

${ }^{24}$ Because of the multiplicative specification adopted in (37) and the fact that the model is loglinearized, changes in $\kappa$ have no effect on the transitional dynamics and the volatility of the credit-tooutput ratio.
} 
less, the union-wide gains are larger for both shocks. This is also the case when the instrument is uniformly set. These effects are also quantitatively large; for the financial shock for instance, and for the case of separate instruments, the gain from coordination is more than twice as large. Intuitively, when credit market imperfections are more pervasive, in the decentralized regime the home country regulator reacts more strongly to changes in the credit-to-output ratio in order to promote financial stability. But given that the foreign country regulator does not find it optimal to react at all, the transmission of shocks is only partly mitigated. In the centralized regime, by contrast, the common regulator internalizes the fact that home country shocks have a larger impact on the foreign economy and sets macroprudential policy instrument (either uniformly or separately) to mitigate financial volatility in both countries.

The second experiment involves heterogeneity in credit market imperfections in member countries. Specifically, we consider the case where $\varphi_{2}$ is kept constant at its benchmark value in the foreign country, but is taken to vary for the home country. As before we calculate the gains from coordination in relative terms, that is, in proportion of outcomes under decentralization.

The results for union-wide gains from coordination are shown in Figure 6, using a grid step of 0.025 for the home country value of $\varphi_{2} \cdot{ }^{25}$ They indicate that the case for international macroprudential policy coordination becomes stronger as countries become more dissimilar in terms of the degree of imperfections in their credit markets and when shocks (real or financial) originate in the country where these imperfections are the strongest. In addition, the gain in response to the productivity shock (which affects directly cyclical output) is larger, compared to the financial shock, by an order of magnitude. The intuition is the same as before; the common regulator's ability to internalize spillovers and spillbacks, which are both magnified with asymmetric credit markets among union members, increases the benefit of delegating macroprudential policy decisions to a supranational entity.

\footnotetext{
${ }^{25}$ This is sufficient for our purpose given that the calculations are fairly time consuming - for each value of $\varphi_{1}$, the optimal value of $\chi_{2}$ must solved for under both regimes and the optimal values of the loss functions is calculated.
} 


\subsection{Correlated Shocks across Countries}

The foregoing analysis has focused on the case of asymmetric shocks occurring in the home country only. With symmetric shocks, given that union members are identical in all respects in the core experiments (including policy preferences), coordination does not generate any gain; but if shocks occur in both countries at the same time while differing in size, one would expect policy responses in the foreign country to be more aggressive and the gain for the union to be positive - albeit lower than those reported in Table 2 for instance.

To confirm these conjectures, the core experiment was repeated under the assumption that shocks in the domestic and foreign countries occur simultaneously but that the shock in the foreign is of the order of 0.8 standard deviation only. The results are not reported in full to save space; but they show that, as expected, a) under Nash, it is optimal for both national regulators to react to the changes in the credit-to-output ratio - with $\chi_{2}=21,18$ and 6,5 for the productivity and financial shocks, respectively, compared to 27, 0 and 7, 0 in Table $2 ; b$ ) the common regulator responds more aggressively — with $\chi_{2}=16.5$ and 5.5 under the uniform instrument for the productivity and financial shocks, respectively, and $\chi_{2}=18,15$ and 6, 5.5 under separate instruments, which are either equal or higher than the corresponding values reported in Table 2; and $c$ ) the gain for the union from coordination is positive, of the order of 0.7 and 0.1 percentage points for the productivity and financial shocks, respectively, when setting separate instruments. However, these gains are also significantly lower compared to when the shock is purely asymmetric across countries - 4.4 and 1.9 percentage points respectively with separate instruments, as reported in Table 2.

\subsection{Asymmetric Country Size}

In the foregoing discussion it was assumed that the two union members are perfectly symmetric in size. We now consider a "core-periphery" setting where the home country is large relatively to the foreign country. Specifically, we set $v=1.6$, which means that the core (home) country is four times larger than the periphery (foreign) country. At the 
same time, all structural parameters are kept the same as in the baseline experiments. ${ }^{26}$

To assess the implications of size for the gains from macroprudential policy coordination, we proceed in two steps. First, we set $v=1.6$ in the common loss functions (57) and (59) only, while keeping symmetric weights $(v=1)$ in the common central bank's Taylor rule (42). This allows us therefore to abstract from the impact of size on the monetary policy channel (discussed earlier) and to isolate the effect of size on the optimal cooperative policy only. Second, we $v=1.6$ both in the common loss functions and the interest rate rule. In either case the union-wide loss function in the decentralized regime is of course aggregated with $v=1.6$.

The results for each scenario are shown in Tables 5 and 6 , where two cases are considered: shocks originating in the core country and shocks (of the same size) originating in the periphery country. In the first case, the results are qualitatively the same as those reported in Table 2-regardless of whether the weights in the monetary policy rule are adjusted or not. In particular, in response to a productivity shock in the home country, coordination entails a loss for that country, regardless of how the common regulator sets its policy instrument. In addition, now both the home country and the union are worse off under cooperation in response to the financial shock when the required reserve ratio is set uniformly. Thus, even at the union level, a one-sizefits-all policy is suboptimal. In terms of magnitude, coordination generates a larger gain for the foreign country, but the gains are generally much smaller for the union as a whole of the order of 0.9 (Table 5) or 0.2 (Table 6) percentage points for the financial shock, compared to 1.9 in the baseline experiment reported in Table 2.

When the shocks originate in the foreign (periphery) country, some of the results are, naturally enough, reversed. In particular, in response to a productivity shock in the foreign country, coordination entails a loss for that country - again, regardless of whether size is accounted for in the monetary policy rule. The intuition behind this result is similar to what was discussed earlier, when shocks were assumed to originate in the home country. In addition, the gains for the union as a whole are of similar

\footnotetext{
${ }^{26}$ Brzoza-Brzezina et al. (2015) follow a similar approach and so do Quint and Rabanal (2014), except for the degree of price rigidities. Note also that the parameter characterizing home bias in the production of the final good in each country remains unchanged.
} 
magnitude as before when size is factored into the setting of the refinance rate (Table 6) but substantially larger otherwise (Table 5): of the order of 8.1 percentage points for the productivity shock and 4 points for the financial shock, compared again to 4.4 and 1.9 points, respectively, in the baseline experiment, when instruments are set separately. ${ }^{27}$ The reason is that the core country benefits relatively more from the monetary policy channel when the common central bank puts equal weights on changes in output and inflation in the periphery (where shocks now originate) in setting the base policy rate, while at the same time the common regulator attaches a higher weight to the core country in solving for the optimal policy.

\section{$8 \quad$ Policy Implications}

As noted in the introduction, the global financial crisis revived interest in the international coordination of financial regulation - in both its structural and countercyclical dimensions. The growing recognition that the overall combination of macroprudential policies may be suboptimal from the perspective of global stability when financial cycles are not synchronized across countries - even when each country's macroprudential policy is optimal at the national level - also contributed to greater emphasis on international coordination.

Our analysis helps to shed some light on the benefits of countercyclical coordination for financial stability in currency unions - including, in our view, the euro area. Although, as noted earlier, the model is not specifically formulated and calibrated for that particular entity, it captures several of its core structural features - including trade in intermediate goods and imperfect capital mobility. In particular, bilateral trade in intermediate inputs represents now a very large share of overall trade flows in goods and services between members of the euro area (see Miroudot et al. (2009)). There is also ample empirical evidence suggesting that, despite significant progress in financial integration in the euro area since 1999, the costs of adjusting cross-border financial positions remain substantial (see Coeurdacier and Rey (2013)) and that credit markets

\footnotetext{
${ }^{27}$ Similar results hold when the macroprudential instrument is set uniformly by the common regulator.
} 
remain insufficiently integrated as a result of differences in practices - in credit risk assessment, for instance - laws and regulations, and market fragmentation (see Weill (2009) and European Central Bank (2015)). This evidence is consistent with our assumptions that capital mobility, although high, is not perfect, and that the cost at which banks borrow from the common central bank depends not only on a base policy rate but also on a country-specific premium. ${ }^{28}$ The evidence also suggests that business cycles remain imperfectly synchronized among member countries (see Giannone et al. (2009), Merler (2015) and Stremmel (2015)), suggesting that idiosyncratic shocks continue to be a major factor in macroeconomic fluctuations in individual countries.

Specifically, our analysis has two main implications for the euro area. The first is related to the institutional design of macroprudential regulation. Within the European Union, the European Banking Authority (EBA), established in January 2011, aims to ensure effective and consistent prudential regulation and supervision across the European banking sector, whereas the European Systemic Risk Board (ESRB), established in December 2010, is responsible for the macroprudential oversight of the financial system, primarily by issuing warnings and recommendations. ${ }^{29}$ In November 2014 the Single Supervisory Mechanism (SSM), under which the European Central Bank (ECB) took on bank and prudential supervisory duties (alongside its previous responsibility for price stability) for the countries that participate in the banking union initiated in 2012 - mostly those of the eurozone - became operative. The objective was to ensure that the SSM and the ECB would interact, with the SSM focusing on microprudential policy and the ECB on monetary policy, in accordance with the separation principle. However, the ECB as the Single Supervisor has mandatory powers over the banking system, leaving no supranational European agency with similar powers over nonbank financial institutions. Moreover, the ECB has the power to set tighter regulatory requirements than national authorities, according to SSM Regulation No. 468 of April 2014. In particular, the ECB may top up specific macroprudential measures-

\footnotetext{
${ }^{28}$ However, the model does not account for cross-border bank lending, an increasingly important feature of financial linkages in the euro zone (see Poutineau and Vermandel (2015)). This issue is discussed further in the conclusion.

${ }^{29}$ At the national level, there are four institutional models for the allocation of macroprudential powers: the government, the central bank, the financial authority, and a committee with representatives from all three of these bodies.
} 
capital instruments, including countercyclical capital buffers and capital surcharges on systemically important institutions, risk weights on real estate exposures, as well as liquidity instruments, such as liquidity coverage ratios - if it considers actions by national authorities to be insufficient to mitigate systemic risks. ${ }^{30}$ Furthermore, national authorities must notify the ECB of their intention to implement macroprudential tools and the ECB can object to them. The very coexistence of four layers of decision-making regarding macroprudential regulation in the European Union (the EBA, the ESRB, the ECB, and national authorities) makes the institutional architecture fairly complex and raises prima facie concerns about coordination, information sharing, and communication in practice. On the issue of coordination specifically, our analysis has implications for interactions between the ECB and national authorities: given the frequency of asymmetric shocks in practice, a high degree of centralization in macroprudential responses may indeed be optimal when countries share similar structural characteristics. Moreover, in that context setting countercyclical policy instruments separately for each country by the common regulator may be preferable to a one-size-fits-all policy.

The second implication is that in a currency union where macroprudential measures can be used, to some degree, as a substitute by national authorities for a national monetary policy, a common regulator who puts more weight on financial stability can achieve superior outcomes in terms of both macroeconomic stability and financial stability in response to financial shocks. Indeed, in a currency union like the euro area where monetary and exchange rate policy instruments are not available, and fiscal policy is constrained by balanced budget rules and debt limits (as a result of the Stability and Growth Pact), national policymakers have few tools to address cyclical conditions. Some observers have argued that to the extent that time-varying macroprudential policy instruments affect aggregate demand (through their impact on credit, asset prices, and interest rates), they may contribute to mitigating output fluctuations in individual member countries - allowing them in a sense to tailor the one-size-fits-all interest rate policy of the currency union. Our analysis shows that when national authorities and

\footnotetext{
${ }^{30}$ Capital instruments are those falling within the scope of the Capital Requirement Regulation (CRR) and Capital Requirement Directive 4 (CRD4), which implement the Basel III Accord. The ECB is required to notify the national authorities, which can object to its measures; but at this moment these objections are not legally binding.
} 
the common regulator both care to the same extent about output stability (while still predominantly focusing on financial stability), coordination still entails some gains, both in terms of lower financial volatility and output volatility, compared to independent policies. However, these gains are magnified-regardless of whether the shocks are real or financial — when the common regulator cares more about financial stability than output stability, compared to national regulators. Put differently, while there is some scope for the ECB to factor in output fluctuations in deciding how macroprudential policies should react to asymmetric shocks between countries of similar size and structure, it should attach a higher weight than national regulators to financial stability in setting its countercyclical responses.

\section{Concluding Remarks}

The purpose of this paper was to contribute, using a game-theoretic approach, to a better understanding of the spillover effects of macroprudential policy in a currency union and to quantify the gains (or lack thereof) associated with countercyclical macroprudential policy coordination in that setting, relative to the case where member countries pursue their own policies. We also assessed how these gains depend on a number of structural characteristics - including the degree of financial integration and the degree of heterogeneity in credit markets across countries. In the model, countries are linked structurally through international trade in intermediate goods and capital flows through bond markets. Both domestic credit market and world capital market imperfections are accounted for. The analysis was initially conducted under the assumption that the countries are of similar size and structure, and that policymakers have distinct institutional mandates - that is, a clear separation in policy responsibilities: monetary policy focusing on the inflation-output trade-off and, conditional on the stance of monetary policy, macroprudential policy geared at mitigating financial risks. The common monetary policy involves setting the refinance rate as the sum of a policy rate and a penalty rate, which depends on the central bank borrowing-required reserves ratio to capture imperfect substitutability between bank deposits and central bank liquidity. We then considered the case where, as in Gelain and Ilbas (2014) for instance, 
the financial regulator is also concerned about output stability (with monetary policy retaining sole responsibility for price stability), and the case where countries are asymmetric, with respect to size and the degree of credit market imperfections. We also examined how the degree of financial integration affects the gains from coordination.

The main results of the paper were summarized in the introduction; to conclude, it is worth highlighting instead some directions in which our analysis can be extended. First, to enhance the analysis of cross-border transmission of financial shocks a unionwide (global) bank lending to home and foreign banks could be introduced, as in Kollmann et al. (2011), Ueda (2012), Kollmann (2013), Alpanda and Aysun (2014) Banerjee et al. (2016), and Nuguer (2016), or alternatively an interbank market where national banks lend to each other, as in Poutineau and Vermandel (2015). In some of these models, banks pay their depositors a premium over the risk-free rate when raising loanable funds and, similar to the standard financial accelerator framework, this spread is made an increasing function of banks' leverage. As a result, the lending rate faced by entrepreneurs in each country would depend not only on borrowers' leverage (as in the standard financial accelerator model) but also on the banks' leverage. Therefore, shocks that affect banks' net worth would have a similar, symmetric effect on risk premia around the world. More generally, this literature suggests that models in which financial frictions only apply to domestic contracts - as is the case in this paper - may not be sufficient for generating a quantitatively large foreign response to domestic shocks. To do so financial frictions many need to be incorporated into international financial contracts as well. Accounting for this type of frictions could magnify the gains from international macroprudential coordination.

Second, the focus of our analysis has been on reserve requirements as the macroprudential policy instrument. A broader or more "generic" interpretation of these requirements, as either a tax on deposits or a tax on lending operating indirectly through the cost of bank borrowing (as for instance in Quint and Rabanal (2014) and Palek and Schwanebeck (2015)) is also legitimate, given that indeed in our framework changes in the required reserve ratio affect market interest rates through changes in the central bank's refinance rate. In addition, as shown by Bianchi (2011) for a generic bank balance sheet, capital and reserve requirements have similar effects and may therefore 
be thought of ex ante (although not ex post) as substitutes from a macroprudential perspective. An extension of the present model to account for both instrumentstaking into account the fact that reserve requirements can be more easily manipulated and at a lower cost - would help to explore further the robustness of our results and their broader policy implications. It would also help to account for the possibility that systemic intermediaries may evade national decisions to adjust capital requirements through regulatory arbitrage - a possibility that, as noted in the introduction, could create another rationale for macroprudential coordination across countries. 


\section{References}

Agénor, Pierre-Richard, and Joshua Aizenman, "Capital Market Imperfections and the Theory of Optimum Currency Areas," Journal of International Money and Finance, 30 (December 2011), 1659-75.

Agénor, Pierre-Richard, Koray Alper, and Luiz Pereira da Silva, "Sudden Floods, Macroprudential Regulation, and Stability in an Open Economy," Journal of International Money and Finance, 48 (November 2014), 68-100.

—_, "External Shocks, Financial Volatility and Reserve Requirements in an Open Economy," Working Paper No. 396, Central Bank of Brazil (August 2015).

Agénor, Pierre-Richard, Leonardo Gambacorta, Enisse Kharroubi, Giovanni Lombardo, and Luiz A. Pereira da Silva, "The International Dimensions of Macroprudential Policies," unpublished, Bank for International Settlements (May 2017).

Aikman, David, Andrew G. Haldane, and Benjamin D. Nelson, "Curbing the Credit Cycle," Economic Journal, 125 (June 2015), 1072-109.

Aiyar, Shekhar, Charles W. Calomiris, and Tomasz Wieladek, "Does Macro-Prudential Regulation Leak? Evidence from a UK Policy Experiment," Journal of Money, Credit and Banking, 46 (February 2014), 181-214.

Alpanda, Sami, and Uluc Aysun, "International Transmission of Financial Shocks in an Estimated DSGE Model," Journal of International Money and Finance, 47 (October 2014), 21-55.

Anundsen, André K., Frank Hansen, Karsten Gerdrup, and Kasper Kragh-Sørensen, "The Role of Credit, House Prices, Non-Core Liabilities and Exuberance Measures for Predicting Financial Crises," Working Paper No. 14/14, Norges Bank (November 2014).

Banerjee, Ryan, Michael B. Devereux, and Giovanni Lombardo, "Self-Oriented Monetary Policy, Global Financial Markets and Excess Volatility of International Capital Flows," Journal of International Money and Finance, 68 (November 2016), 275-97.

Bank for International Settlements, Annual Report (June 2016).

Beirne, John, and Christian Friedrich, "Capital Flows and Macroprudential Policies: A Multilateral Assessment of Effectiveness and Externalities," Working Paper No. 1721, European Central Bank (August 2014).

Bengui, Julien, "Macro-Prudential Policy Coordination," unpublished, University of Montréal (April 2014).

Benigno, Gianluca, and Pierpaolo Benigno, "Implementing International Monetary Cooperation through Inflation Targeting," Macroeconomic Dynamics, 12 (April 2008), 45-59.

Bergin, Paul R., Hyung-Cheol Shin, and Ivan Tchakarov, "Does Exchange Rate Variability Matter for Welfare? A Quantitative Investigation of Stabilization Policies," European Economic Review, 51 (May 2007), 1041-58.

Bianchi, Javier, "Overborrowing and Systemic Externalities in the Business Cycle," American Economic Review, 101 (December 2011), 3400-26.

Bodenstein, Martin, Luca Guerrieri, and Joe LaBriola, "Macroeconomic Policy Games," unpublished, Universit of California Berkeley (September 2014). 
Braun, R. Anton, and Tomoyuki Nakajima, "Making the Case for a Low Intertemporal Elasticity of Substitution," Working Paper No. 2012-1, Federal Reserve Bank of Atlanta (January 2012).

Brzoza-Brzezina, Michał, Marcin Kolasa, and Krzysztof Makarski, "Macroprudential Policy and Imbalances in the Euro Area," Journal of International Money and Finance, 51 (March 2015), 137-54.

Cerutti, Eugenio, Stijn Claessens, and Luc Laeven, "The Use and Effectiveness of Macroprudential Policies: New Evidence," Journal of Financial Stability, 28 (February 2017), 203-24.

Christoffel, Kai, and Andreas Schabert, "Interest Rates, Money, and Banks in an Estimated Euro Area Model," Working Paper No. 1791, European Central Bank (May 2015).

Coenen, Günter, Giovanni Lombardo, Frank Smets, and Roland Straub, "International Transmission and Monetary Policy Cooperation," in International Dimensions of Monetary Policy, ed. by Jordi Galí and Mark Gertler, University of Chicago Press (Chicago, Ill.: 2009).

Coeurdacier, Nicolas, and Hélène Rey, "Home Bias in Open Economy Financial Macroeconomics," Journal of Economic Literature, 51 (March 2013), 63-115.

Committee on the Global Financial System, "Objective-Setting and Communication of Macroprudential Policies," CGFS Paper No. 57 (November 2016).

Corsetti, Giancarlo, Keith Kuester, André Meier, Gernot J. Müller, "Sovereign Risk and Belief-Driven Fluctuations in the Euro Area," Journal of Monetary Economics, 61 (January 2014), 53-73.

Cuadra, Gabriel, and Victoria Nuguer, "Risky Banks and Macroprudential Policy for Emerging Economies," unpublished, Bank of Mexico (December 2014).

Darracq Pariès, Matthieu, Christoffer Kok Sorensen, and Diego Rodriguez Palenzuela, "Macroeconomic Propagation under Different Regulatory Regimes: Evidence from an Estimated DSGE Model for the Euro Area," International Journal of Central Banking, 7 (December 2011), 49-113.

Djankov, Simeon, Oliver Hart, Caralee McLiesh, and Andrei Shleifer, "Debt Enforcement around the World," Journal of Political Economy, 116 (December 2008), 1105-49.

Eichengreen, Barry, "International Policy Coordination: The Long View," in Globalization in an Age of Crisis, ed. by Robert Feenstra and Alan Taylor, University of Chicago Press (Chicago, Ill.: 2014).

Engel, Charles, "International Coordination of Central Bank Policy," Journal of International Money and Finance, 67 (October 2016), 13-24.

European Central Bank, Financial Integration in Europe, ECB Publications (Frankfurt: April 2015).

Faia, Ester, "Financial Differences and Business Cycle Co-Movements in a Currency Area," Journal of Money, Credit and Banking, 39 (February 2007), 151-85.

Fujiwara, Ippei, and Yuki Teranishi, "Financal Frictions and Policy Cooperation: A Case with Monopolistic Banking and Staggered Loan Contracts," forthcoming, Journal of International Economics (January 2017). 
Gelain, Paolo, and Pelin Ilbas, "Monetary and Macroprudential Policies in an Estimated Model with Financial Intermediation," Working Paper No. 258, National Bank of Belgium (May 2014).

Gerali, Andrea, Stefano Neri, Luca Sessa, and Federico M. Signoretti, "Credit and Banking in a DSGE Model of the Euro Area," Journal of Money, Credit, and Banking, 42 (September 2010), 107-41.

Giannone, Domenico, Michele Lenza, and Lucrezia Reichlin, "Business Cycles in the Euro Area," Working Paper No. 1010, European Central Bank (February 2009).

Gilchrist, Simon, "Financial Markets and Financial Leverage in a Two-Country World Economy," in Banking Market Structure and Monetary Policy, ed. by Luis A. Ahumada and J. Rodrigo Fuentes, Central Bank of Chile (Santiago: 2004).

Gong, Liutang, Chan Wang, and Heng-fu Zou, "Optimal Monetary Policy with International Trade in Intermediate Inputs," Journal of International Money and Finance, 65 (July 2016), 140-65.

Huang, Kevin X., and Zheng Liu, "Business Cycles with Staggered Prices and International Trade in Intermediate Inputs," Journal of Monetary Economics, 54 (May 2007), 127189.

International Monetary Fund, Global Financial Stability Report, IMF Publications (Washington DC: April 2016).

Ireland, Peter N., "Sticky-Price Models of the Business Cycle: Specification and Stability," Journal of Monetary Economics, 47 (March 2001), 3-18.

Jeanne, Olivier, "Macroprudential Policies in a Global Perspective," Working Paper No. 19967, National Bureau of Economic Research (March 2014).

Kara, Gazi I., "Systemic Risk, International Regulation, and the Limits of Coordination," Journal of International Economics, 99 (March 2016), 192-222.

Kashyap, Anil K., and Jeremy C. Stein, "The Optimal Conduct of Monetary Policy with Interest on Reserves," American Economic Journal: Macroeconomics, 4 (January 2012), 266-82.

Kolasa, Marcin, and Giovanni Lombardo, "Financial Frictions and Optimal Monetary Policy in an Open Economy," International Journal of Central Banking, 44 (March 2014), 43-94.

Kollmann, Robert, "Monetary Policy Rules in an Interdependent World," Discussion Paper No. 4012, Centre for Economic Policy Research (August 2003).

—_, "Global Banks, Financial Shocks, and International Business Cycles: Evidence from an Estimated Model," Journal of Money, Credit and Banking, 45 (December 2013), 159-95.

Kollmann, Robert, Zeno Enders, and Gernot J. Müller, "Global Banking and International Business Cycles," European Economic Review, 55 (April 2011), 407-26.

Korinek, Anton, "International Spillovers and Guidelines for Policy," unpublished, Johns Hopkins University (October 2014).

— - "Currency Wars or Efficient Spillovers? A General Theory of International Policy Cooperation," Working Paper No. 17/25, International Monetary Fund (February 2017). 
Liu, Zheng, and Evi Pappa, "Gains from International Monetary Policy Coordination: Does it Pay to Be Different?," Journal of Economic Dynamics and Control, 32 (July 2008), 2085-117.

Mendicino, Caterina, and Maria T. Punzi, "House Prices, Capital Inflows and Macroprudential Policy," Journal of Banking and Finance, 49 (December 2014), 337-55.

Merler, Silvia, "Squaring the Cycle: Financial Cycles, Capital Flows and Macroprudential Policy in the Euro Area," Working Paper No. 15/14, Bruegel (November 2015).

Miroudot, Sébastien, Rainer Lanz, and Alexandros Ragoussis, "Trade in Intermediate Goods and Services," Trade Policy Paper No. 93, OECD (November 2009).

Nuguer, Victoria, "Financial Intermediation in a Global Environment," International Journal of Central Banking, 13 (September 2016), 291-344.

Palek, Jakob, and Benjamin Schwanebeck, "Optimal Monetary and Macroprudential Policy in a Currency Union," MAGKS Discussion Paper No. 2015- 22, Philipps-University Marburg (July 2015). Forthcoming, Economic Modelling.

Pappa, E., "Do the ECB and the Fed really Need to Cooperate? Optimal Monetary Policy in a Two-Country World," Journal of Monetary Economics, 51 (May 2004), 753-79.

Poutineau, Jean C., and Gauthier Vermandel, "Cross-border Banking Flows Spillovers in the Eurozone: Evidence from an Estimated DSGE Model," Journal of Economic Dynamics and Control, 51 (February 2015), 378-403.

Quint, Dominic, and Pau Rabanal, "Monetary and Macroprudential Policy in an Estimated DSGE Model of the Euro Area," International Journal of Central Banking, 10 (June 2014), 169-236.

Rubio, Margarita, "Macroprudential Policy Implementation in a Heterogeneous Monetary Union," unpublished, University of Nottingham (March 2014).

Rubio, Margarita, and José A. Carrasco-Gallego, "Coordinating Macroprudential Policies within the Euro Area: The Case of Spain," Economic Modelling, 59 (December 2016), 570-82.

Sergeyev, Dmitriy, "Optimal Macroprudential and Monetary Policy in a Currency Union," unpublished, Bocconi University (June 2016).

Stremmel, Hanno, "Capturing the Financial Cycle in Europe," Working Paper No. 1811, European Central Bank (June 2015).

Sutherland, Alan, "International Monetary Policy Coordination and Financial Market Integration," Discussion Paper No. 4251, Centre for Economic Policy Research (February 2004).

Taylor, Alan M., "Credit, Financial Stability, and the Macroeconomy," Working Paper No. 21039, National Bureau of Economic Research (March 2015).

Taylor, John B., "International Monetary Policy Coordination: Past, Present and Future," Working Paper No. 437, Bank for International Settlements (December 2013).

Thimme, Julian, "Intertemporal Substitution in Consumption: A Literature Review," Journal of Economic Surveys, 31 (February 2017), 226-57.

Tomura, Hajime, "International Capital Flows and Expectation-Driven Boom-Bust Cycles in the Housing Market," Journal of Economic Dynamics and Control, 34 (October 2010), 1993-2009. 
Ueda, Kazuo, "Banking Globalization and International Business Cycles: Cross-Border Chained Credit Contracts and Financial Accelerators," Journal of International Economics, 86 (January 2012), 1-16.

Weill, Laurent, "Convergence in Banking Efficiency across European Countries," Journal of International Financial Markets, Institutions and Money, 20 (December 2009), 81833. 
Table 1

Benchmark Parameterization: Key Parameter Values

\begin{tabular}{|c|c|c|}
\hline Parameter & Value & Description \\
\hline \multicolumn{3}{|l|}{ Household } \\
\hline$\beta$ & 0.99 & Discount factor \\
\hline$\varsigma$ & 0.5 & Elasticity of intertemporal substitution \\
\hline$\eta_{N}$ & 10.0 & Preference parameter for leisure \\
\hline$\eta_{x}$ & 0.02 & Preference parameter for money holdings \\
\hline$\eta_{A}$ & 0.02 & Preference parameter for housing \\
\hline$\nu$ & 0.2 & Share parameter in index of money holdings \\
\hline$\theta_{0}^{B}$ & 0.1 & Sensitivity of risk premium, bond holdings \\
\hline \multicolumn{3}{|l|}{ Production } \\
\hline$\Lambda_{I}$ & 0.7 & Share of home IG goods in final output \\
\hline$\eta$ & 1.5 & Elasticity of substitution, baskets of IG goods \\
\hline$\theta_{H H}, \theta_{F F}$ & 10.0 & Elasticity of demand, intermediate goods \\
\hline$\alpha$ & 0.35 & Share of capital, domestic intermediate goods \\
\hline$\phi_{D}$ & 74.5 & Adjustment cost parameter, domestic IG prices \\
\hline$\delta$ & 0.025 & Depreciation rate of capital \\
\hline$\Theta_{K}$ & 14 & Adjustment cost parameter, investment \\
\hline \multicolumn{3}{|c|}{ Commercial Bank } \\
\hline$\kappa$ & 0.2 & Effective collateral-loan ratio \\
\hline$\varphi_{1}$ & 0.05 & Elasticity of repayment probability, collateral \\
\hline$\varphi_{2}$ & 0.2 & Elasticity of repayment probability, cyclical output \\
\hline \multicolumn{3}{|c|}{ Common central bank } \\
\hline$\mu$ & 0.08 & Reserve requirement rate \\
\hline$\chi$ & 0.8 & Degree of interest rate smoothing \\
\hline$\varepsilon_{1}$ & 1.6 & Response of base policy rate to inflation deviations \\
\hline$\varepsilon_{2}$ & 0.15 & Response of base policy rate to output deviations \\
\hline$\theta_{0}^{C B}$ & 0.0007 & Steady-state penalty rate \\
\hline$\chi^{C B}$ & 1.1 & Elasticity of penalty rate to borrrowing-reserves ratio \\
\hline$\chi_{1}$ & 0.1 & Persistence parameter, reserve requirements rule \\
\hline Government & & \\
\hline$\psi$ & 0.18 & Share of government spending in domestic output sales \\
\hline \multicolumn{3}{|r|}{ 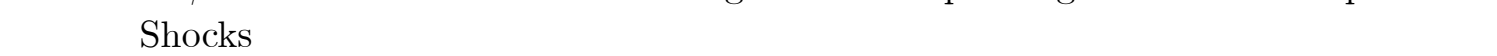 } \\
\hline$\rho^{Y}$ & 0.8 & Persistence parameter, productivity shock \\
\hline$\rho^{Q}$ & 0.57 & Persistence parameter, financial shock \\
\hline
\end{tabular}


Table 2

Optimal Policy Responses and Policy Gains or Losses under Centralized and Decentralized Regimes: Narrow and Broad Measures of Financial Stability

\begin{tabular}{|c|c|c|c|c|}
\hline & \multicolumn{2}{|c|}{ " Narrow Measure of Financial Stability } & \multicolumn{2}{|c|}{ "Broad Measure of Financial Stability } \\
\hline & Productivity shock & Financial shock & Productivity shock & Financial shock \\
\hline \multicolumn{5}{|l|}{ No countercyclical policy response } \\
\hline Policy loss-Home member & 0.0083 & 0.0012 & 0.0149 & 0.0012 \\
\hline Policy loss-Foreign member & 0.0038 & 0.0007 & 0.0105 & 0.0008 \\
\hline Policy loss-Union & 0.0060 & 0.0010 & 0.0127 & 0.0010 \\
\hline \multicolumn{5}{|l|}{ Decentralized regime (Nash) } \\
\hline Optimal response parameters, $\chi_{2}^{\mathrm{H}}, \chi_{2}^{\mathrm{F}}$ & 27,0 & 7,0 & 24,0 & 6,0 \\
\hline Policy loss-Home member & 0.0062 & 0.0009 & 0.0098 & 0.0009 \\
\hline Policy loss-Foreign member & 0.0025 & 0.0004 & 0.0057 & 0.0005 \\
\hline Policy loss-Union & 0.0043 & 0.0006 & 0.0078 & 0.0007 \\
\hline \multicolumn{5}{|l|}{ Centralized regime (Cooperation) } \\
\hline \multicolumn{5}{|l|}{ Uniform instrument } \\
\hline Optimal response parameter, $\chi_{2}$ & 15 & 5.5 & 13.5 & 5 \\
\hline Policy loss-Home member & 0.0064 & 0.0009 & 0.0100 & 0.0009 \\
\hline Policy loss-Foreign member & 0.0020 & 0.0004 & 0.0054 & 0.0005 \\
\hline Policy loss-Union & 0.0042 & 0.0006 & 0.0077 & 0.0007 \\
\hline \multicolumn{5}{|l|}{ Separate instruments } \\
\hline Optimal response parameters, $\chi_{2}^{\mathrm{H}}, \chi_{2}^{\mathrm{F}}$ & 18,3 & 6,1 & $19.5,3$ & $5.5,1$ \\
\hline Policy loss-Home member & 0.0063 & 0.0009 & 0.0100 & 0.0009 \\
\hline Policy loss-Foreign member & 0.0019 & 0.0004 & 0.0053 & 0.0005 \\
\hline Policy loss-Union & 0.0041 & 0.0006 & 0.0077 & 0.0007 \\
\hline \multicolumn{5}{|l|}{ Net gain or loss from coordination ${ }^{1}$} \\
\hline \multicolumn{5}{|l|}{ Uniform instrument } \\
\hline Home member & 0.0351 & -0.0036 & 0.0206 & -0.0020 \\
\hline Foreign member & -0.1933 & -0.0299 & -0.0426 & -0.0196 \\
\hline Union & -0.0300 & -0.0113 & -0.0024 & -0.0083 \\
\hline \multicolumn{5}{|l|}{ Separate instruments } \\
\hline Home member & 0.0235 & -0.0073 & 0.0199 & -0.0036 \\
\hline Foreign member & -0.2117 & -0.0469 & -0.0620 & -0.0225 \\
\hline Union & -0.0435 & -0.0188 & -0.0100 & -0.0104 \\
\hline
\end{tabular}

Note: As defined in the text, the narrow measure of financial stability involves only the volatility of the credit-to-output ratio, whereas the broad measure of financial stability attaches weights of 0.85 to the volatility of the credit-to-output ratio and 0.15 to the volatility of real house prices.

${ }^{1}$ In percent. A negative entry means a net policy gain from cooperation relative to Nash.

Source: Authors' calculations. 
Table 3

Optimal Policy Responses and Policy Gains or Losses under Centralized and Decentralized Regimes:

Symmetric and Asymmetric Policy Preferences for Output Stability

\begin{tabular}{|c|c|c|c|c|}
\hline & \multicolumn{2}{|c|}{ Symmetric Preferences, Output Stability } & \multicolumn{2}{|c|}{ "Asymmetric Preferences, Output Stability } \\
\hline & Productivity shock & Financial shock & Productivity shock & Financial shock \\
\hline \multicolumn{5}{|l|}{ No countercyclical policy response } \\
\hline Policy loss-Home member & 0.0124 & 0.0034 & 0.0116 & 0.0031 \\
\hline Policy loss-Foreign member & 0.0050 & 0.0010 & 0.0048 & 0.0010 \\
\hline Policy loss-Union & 0.0087 & 0.0022 & 0.0082 & 0.0020 \\
\hline \multicolumn{5}{|l|}{ Decentralized regime (Nash) } \\
\hline Optimal response parameters, $\chi_{2}^{\mathrm{H}}, \chi_{2}^{\mathrm{F}}$ & $10.5,0$ & 4,0 & $10.5,0$ & 4,0 \\
\hline Policy loss-Home member & 0.0114 & 0.0033 & 0.0114 & 0.0033 \\
\hline Policy loss-Foreign member & 0.0039 & 0.0007 & 0.0039 & 0.0007 \\
\hline Policy loss-Union & 0.0076 & 0.0020 & 0.0076 & 0.0020 \\
\hline \multicolumn{5}{|l|}{ Centralized regime (Cooperation) } \\
\hline \multicolumn{5}{|l|}{ Uniform instrument } \\
\hline Optimal response parameter, $\chi_{2}$ & 6 & 3 & 6 & 3 \\
\hline Policy loss-Home member & 0.0116 & 0.0033 & 0.0108 & 0.0033 \\
\hline Policy loss-Foreign member & 0.0034 & 0.0006 & 0.0035 & 0.0005 \\
\hline Policy loss-Union & 0.0075 & 0.0020 & 0.0072 & 0.0019 \\
\hline \multicolumn{5}{|l|}{ Separate instruments } \\
\hline Optimal response parameters, $\chi_{2}^{\mathrm{H}}, \chi_{2}^{\mathrm{F}}$ & 9,3 & $3.5,0.5$ & 9,3 & $3.5,0.5$ \\
\hline Policy loss-Home member & 0.0115 & 0.0033 & 0.0106 & 0.0032 \\
\hline Policy loss-Foreign member & 0.0035 & 0.0006 & 0.0037 & 0.0005 \\
\hline Policy loss-Union & 0.0075 & 0.0020 & 0.0071 & 0.0019 \\
\hline \multicolumn{5}{|l|}{ Net gain or loss from coordination ${ }^{1}$} \\
\hline \multicolumn{5}{|l|}{ Uniform instrument } \\
\hline Home member & 0.0208 & -0.0026 & -0.0494 & -0.0165 \\
\hline Foreign member & -0.1257 & -0.0487 & -0.0942 & -0.2375 \\
\hline Union & -0.0163 & -0.0102 & -0.0607 & -0.0531 \\
\hline \multicolumn{5}{|l|}{ Separate instruments } \\
\hline Home member & 0.0073 & -0.0040 & -0.0666 & -0.0255 \\
\hline Foreign member & -0.0962 & -0.0759 & -0.0549 & -0.2223 \\
\hline Union & -0.0189 & -0.0159 & -0.0636 & -0.0581 \\
\hline
\end{tabular}

Note: As discussed in the text, symmetric policy preferences with respect to output stability involves both national regulators and the common regulator atttaching a weight of 0.9 to financial stability, measured in terms of the volatility of the credit-to-output ratio, and 0.1 to output volatility. Unser asymmetric policy preferences, national regulators use the exact same weights, whereas the common regulatgor attaches a weight of 0.95 to financial stability and 0.05 to output volatility.

${ }^{1}$ In percent. A negative entry means a net policy gain from cooperation relative to Nash.

Source: Authors' calculations. 
Table 4

Optimal Policy Responses and Policy Gains or Losses under Centralized and Decentralized Regimes: Greater Financial Integration and Degree of Credit Market Imperfections

\begin{tabular}{|c|c|c|c|c|}
\hline & \multicolumn{2}{|c|}{ Greater Financial Integration $\left(\theta_{0}^{\mathrm{B}}=0.05\right)$} & \multicolumn{2}{|c|}{ Credit Market Imperfections $\left(\varphi_{2}=0.25\right)$} \\
\hline & Productivity shock & Financial shock & Productivity shock & Financial shock \\
\hline \multicolumn{5}{|l|}{ No countercyclical policy response } \\
\hline Policy loss-Home member & 0.0081 & 0.0010 & 0.0083 & 0.0010 \\
\hline Policy loss-Foreign member & 0.0040 & 0.0008 & 0.0038 & 0.0008 \\
\hline Policy loss-Union & 0.0060 & 0.0009 & 0.0060 & 0.0009 \\
\hline \multicolumn{5}{|l|}{ Decentralized regime (Nash) } \\
\hline Optimal response parameters, $\chi_{2}^{\mathrm{H}}, \chi_{2}^{\mathrm{F}}$ & 27,0 & 7,0 & $28.5,0$ & $6.5,0$ \\
\hline Policy loss-Home member & 0.0062 & 0.0007 & 0.0061 & 0.0007 \\
\hline Policy loss-Foreign member & 0.0027 & 0.0004 & 0.0024 & 0.0004 \\
\hline Policy loss-Union & 0.0044 & 0.0006 & 0.0043 & 0.0005 \\
\hline \multicolumn{5}{|l|}{ Centralized regime (Cooperation) } \\
\hline \multicolumn{5}{|l|}{ Uniform instrument } \\
\hline Optimal response parameter, $\chi_{2}$ & 13.5 & 5 & 15 & 5 \\
\hline Policy loss-Home member & 0.0062 & 0.0007 & 0.0063 & 0.0007 \\
\hline Policy loss-Foreign member & 0.0021 & 0.0004 & 0.0019 & 0.0003 \\
\hline Policy loss-Union & 0.0042 & 0.0005 & 0.0041 & 0.0005 \\
\hline \multicolumn{5}{|l|}{ Separate instruments } \\
\hline Optimal response parameters, $\chi_{2}^{\mathrm{H}}, \chi_{2}^{\mathrm{F}}$ & 18,3 & $5.5,1$ & 18,3 & $5.5,1$ \\
\hline Policy loss-Home member & 0.0060 & 0.0007 & 0.0060 & 0.0007 \\
\hline Policy loss-Foreign member & 0.0021 & 0.0004 & 0.0021 & 0.0003 \\
\hline Policy loss-Union & 0.0041 & 0.0005 & 0.0041 & 0.0005 \\
\hline \multicolumn{5}{|l|}{ Net gain or loss from coordination ${ }^{1}$} \\
\hline \multicolumn{5}{|l|}{ Uniform instrument } \\
\hline Home member & -0.0019 & -0.0251 & 0.0382 & -0.0070 \\
\hline Foreign member & -0.2026 & -0.0808 & -0.2036 & -0.0376 \\
\hline Union & -0.0622 & -0.0441 & -0.0313 & -0.0171 \\
\hline \multicolumn{5}{|l|}{ Separate instruments } \\
\hline Home member & -0.0265 & -0.0267 & -0.0027 & -0.0086 \\
\hline Foreign member & -0.2165 & -0.0888 & -0.1457 & -0.0569 \\
\hline Union & -0.0836 & -0.0479 & -0.0466 & -0.0245 \\
\hline
\end{tabular}

Note: As defined in the text, the degree of financial integration is measured by $\theta_{0}^{B}$, the sensitivity of the risk premium to bond holdings, whereas the degree of credit market imperfections is measured by $\varphi_{2}$, the sensitivity of the repayment probability with respect to cyclical output.

${ }^{1}$ In percent. A negative entry means a net policy gain from cooperation relative to Nash.

Source: Authors' calculations. 
Table 5

Optimal Policy Responses and Policy Gains or Losses under Centralized and Decentralized Regimes: Asymmetric Size for Common Loss Function, Equal Size for Monetary Policy Rule

\begin{tabular}{|c|c|c|c|c|}
\hline & \multicolumn{2}{|c|}{ Shock Originating in the Home country } & \multicolumn{2}{|c|}{ Shock Originating in the Foreign country } \\
\hline & Productivity shock & Financial shock & Productivity shock & Financial shock \\
\hline \multicolumn{5}{|l|}{ No countercyclical policy response } \\
\hline Policy loss-Home member & 0.0083 & 0.0012 & 0.0038 & 0.0007 \\
\hline Policy loss-Foreign member & 0.0038 & 0.0007 & 0.0083 & 0.0012 \\
\hline Policy loss-Union & 0.0074 & 0.0011 & 0.0047 & 0.0008 \\
\hline \multicolumn{5}{|l|}{ Decentralized regime (Nash) } \\
\hline Optimal response parameters, $\chi_{2}^{\mathrm{H}}, \chi_{2}^{\mathrm{F}}$ & 27,0 & 7,0 & 0,27 & 0,7 \\
\hline Policy loss-Home member & 0.0062 & 0.0009 & 0.0025 & 0.0004 \\
\hline Policy loss-Foreign member & 0.0025 & 0.0004 & 0.0062 & 0.0009 \\
\hline Policy loss-Union & 0.0054 & 0.0008 & 0.0032 & 0.0005 \\
\hline \multicolumn{5}{|l|}{ Centralized regime (Cooperation) } \\
\hline \multicolumn{5}{|l|}{ Uniform instrument } \\
\hline Optimal response parameter, $\chi_{2}$ & 16.5 & 6 & 12 & 5.5 \\
\hline Policy loss-Home member & 0.0064 & 0.0009 & 0.0021 & 0.0004 \\
\hline Policy loss-Foreign member & 0.0021 & 0.0004 & 0.0064 & 0.0009 \\
\hline Policy loss-Union & 0.0055 & 0.0008 & 0.0030 & 0.0005 \\
\hline \multicolumn{5}{|l|}{ Separate instruments } \\
\hline Optimal response parameters, $\chi_{2}^{\mathrm{H}}, \chi_{2}^{\mathrm{F}}$ & 21,3 & $6.5,1$ & 3,15 & 1,6 \\
\hline Policy loss-Home member & 0.0062 & 0.0009 & 0.0021 & 0.0003 \\
\hline Policy loss-Foreign member & 0.0021 & 0.0003 & 0.0062 & 0.0009 \\
\hline Policy loss-Union & 0.0054 & 0.0008 & 0.0029 & 0.0005 \\
\hline \multicolumn{5}{|l|}{ Net gain or loss from coordination ${ }^{1}$} \\
\hline \multicolumn{5}{|l|}{ Uniform instrument } \\
\hline Home member & 0.0337 & 0.0301 & -0.1453 & -0.0601 \\
\hline Foreign member & -0.1453 & -0.0601 & 0.0337 & 0.0301 \\
\hline Union & 0.0175 & 0.0217 & -0.0764 & -0.0259 \\
\hline \multicolumn{5}{|l|}{ Separate instruments } \\
\hline Home member & 0.0083 & -0.0032 & -0.1367 & -0.0621 \\
\hline Foreign member & -0.1367 & -0.0621 & 0.0083 & -0.0032 \\
\hline Union & -0.0048 & -0.0086 & -0.0808 & -0.0398 \\
\hline
\end{tabular}

Note: Weights in the policy loss function are 0.8 for the home member and 0.2 for the foreign member.

${ }^{1}$ In percent. A negative entry means a net policy gain from cooperation relative to Nash.

Source: Authors' calculations. 
Table 6

Optimal Policy Responses and Policy Gains or Losses under Centralized and Decentralized Regimes: Asymmetric Size for both Common Loss Function and Monetary Policy Rule

\begin{tabular}{|c|c|c|c|c|}
\hline & \multicolumn{2}{|c|}{ Shock Originating in the Home country } & \multicolumn{2}{|c|}{ Shock Originating in the Foreign country } \\
\hline & Productivity shock & Financial shock & Productivity shock & Financial shock \\
\hline \multicolumn{5}{|l|}{ No countercyclical policy response } \\
\hline Policy loss-Home member & 0.0086 & 0.0012 & 0.0041 & 0.0008 \\
\hline Policy loss-Foreign member & 0.0041 & 0.0008 & 0.0086 & 0.0012 \\
\hline Policy loss-Union & 0.0077 & 0.0011 & 0.0050 & 0.0009 \\
\hline \multicolumn{5}{|l|}{ Decentralized regime (Nash) } \\
\hline Optimal response parameters, $\chi_{2}^{\mathrm{H}}, \chi_{2}^{\mathrm{F}}$ & 27,0 & $7.5,0$ & 0,27 & $0,7.5$ \\
\hline Policy loss-Home member & 0.0061 & 0.0009 & 0.0023 & 0.0004 \\
\hline Policy loss-Foreign member & 0.0023 & 0.0004 & 0.0061 & 0.0009 \\
\hline Policy loss-Union & 0.0054 & 0.0008 & 0.0031 & 0.0005 \\
\hline \multicolumn{5}{|l|}{ Centralized regime (Cooperation) } \\
\hline \multicolumn{5}{|l|}{ Uniform instrument } \\
\hline Optimal response parameter, $\chi_{2}$ & 18 & 6.5 & 15 & 6 \\
\hline Policy loss-Home member & 0.0063 & 0.0010 & 0.0020 & 0.0004 \\
\hline Policy loss-Foreign member & 0.0020 & 0.0004 & 0.0063 & 0.0010 \\
\hline Policy loss-Union & 0.0055 & 0.0008 & 0.0029 & 0.0005 \\
\hline \multicolumn{5}{|l|}{ Separate instruments } \\
\hline Optimal response parameters, $\chi_{2}^{\mathrm{H}}, \chi_{2}^{\mathrm{F}}$ & 24,3 & 7,1 & 3,18 & $1,6.5$ \\
\hline Policy loss-Home member & 0.0061 & 0.0009 & 0.0021 & 0.0004 \\
\hline Policy loss-Foreign member & 0.0021 & 0.0004 & 0.0061 & 0.0009 \\
\hline Policy loss-Union & 0.0053 & 0.0008 & 0.0029 & 0.0005 \\
\hline \multicolumn{5}{|l|}{ Net gain or loss from coordination ${ }^{1}$} \\
\hline \multicolumn{5}{|l|}{ Uniform instrument } \\
\hline Home member & 0.0324 & 0.0365 & -0.1200 & -0.0650 \\
\hline Foreign member & -0.1200 & -0.0650 & 0.0324 & 0.0365 \\
\hline Union & 0.0193 & 0.0272 & -0.0593 & -0.0263 \\
\hline \multicolumn{5}{|l|}{ Separate instruments } \\
\hline Home member & 0.0035 & -0.0004 & -0.0812 & -0.0217 \\
\hline Foreign member & -0.0812 & -0.0217 & 0.0035 & -0.0004 \\
\hline Union & -0.0038 & -0.0024 & -0.0475 & -0.0136 \\
\hline
\end{tabular}

Note: Weights in the policy loss function and the interest rate rule are 0.8 for the home member and 0.2 for the foreign member.

${ }^{1}$ In percent. A negative entry means a net policy gain from cooperation relative to Nash.

Source: Authors' calculations. 
Figure 1

Model Structure: Home \&RXQN

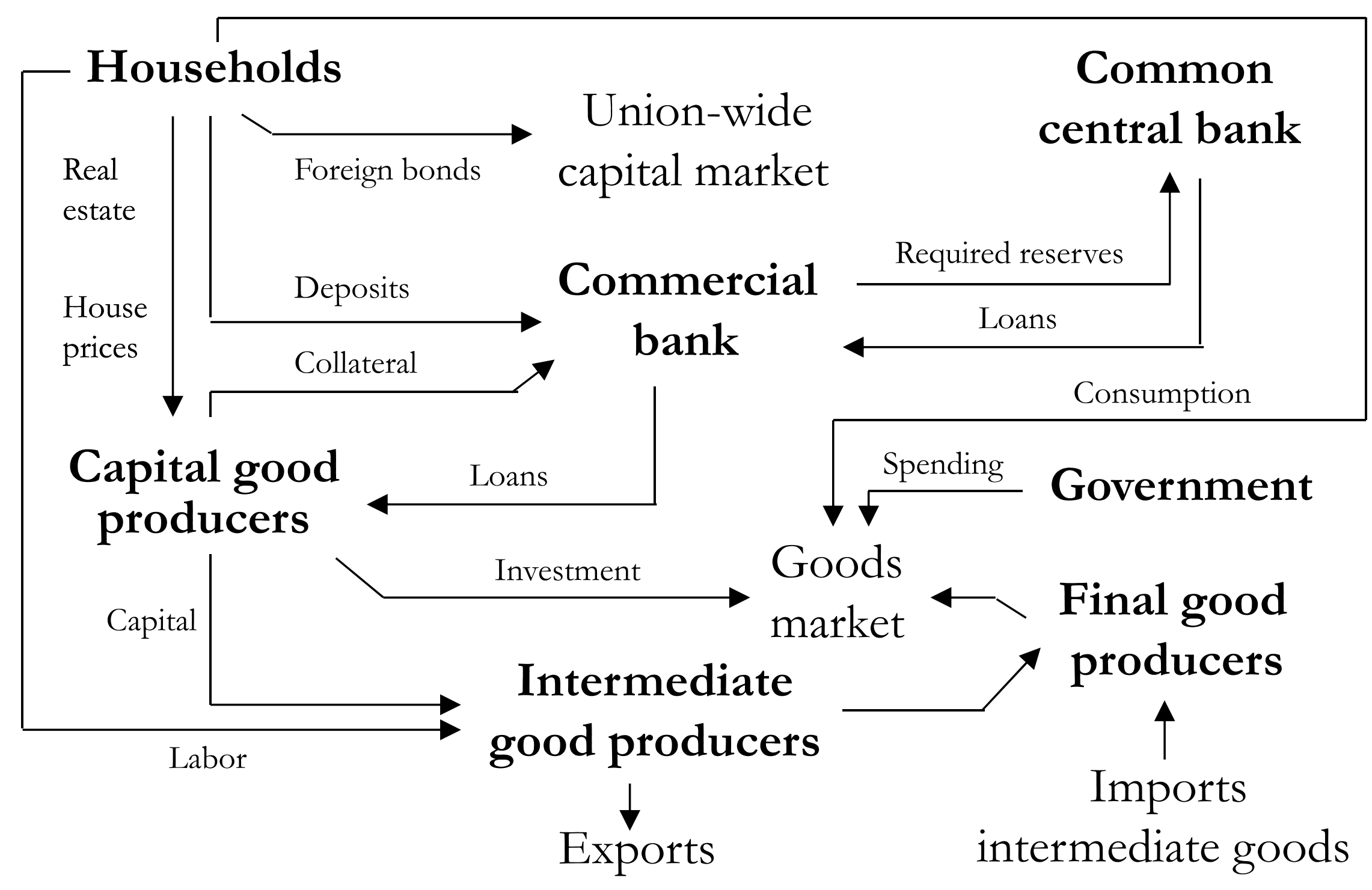




\section{Figure 2}

\section{Positive Productivity Shock in Home Country}

(Deviations from steady state)
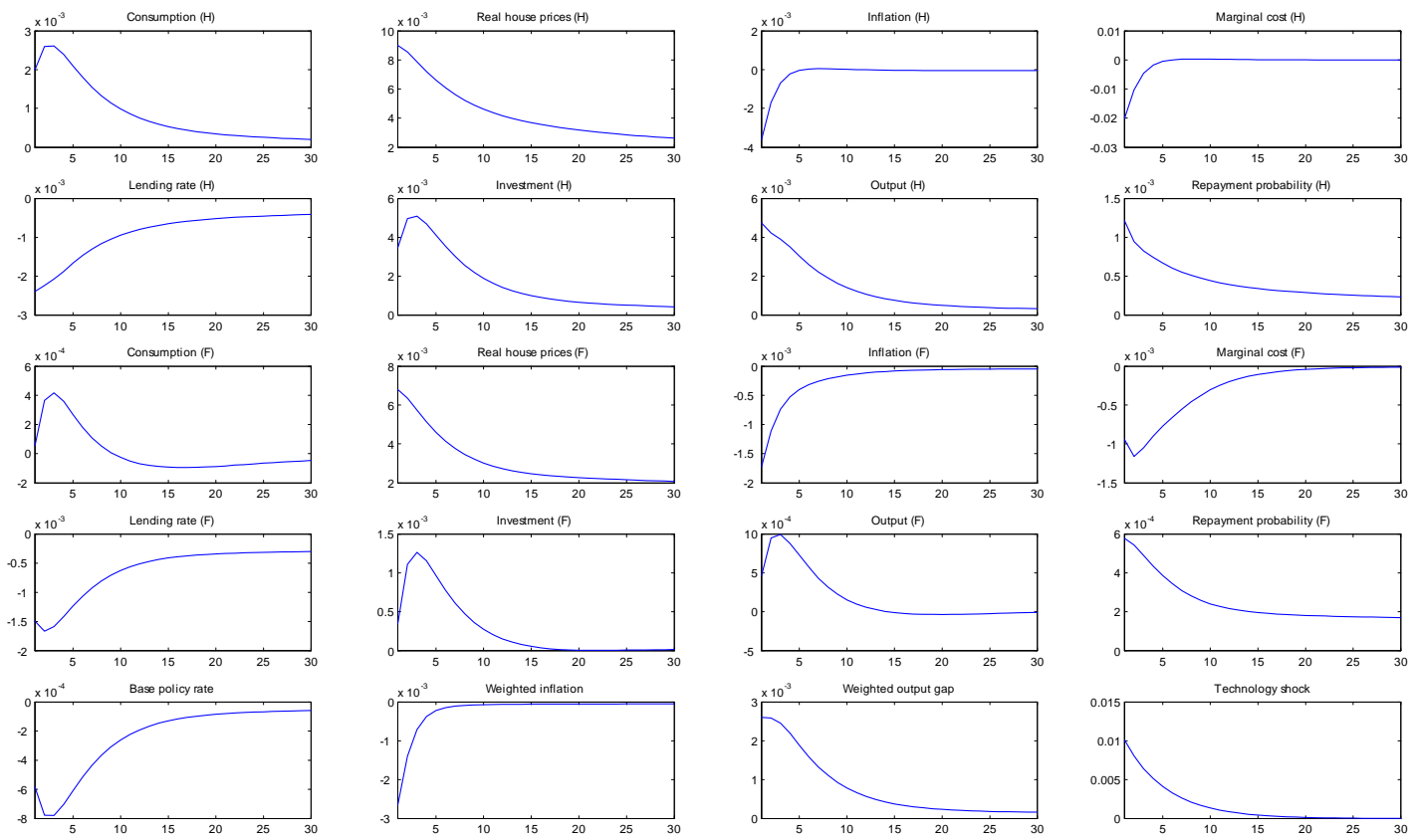

Note: Interest rates, inflation rate and the repayment probability are measured in absolute deviations, that is, in the relevant graphs a value of 0.05 for these variables corresponds to a 5 percentage point deviation in absolute terms. 
Figure 3

Negative Financial Shock in Home Country

(Deviations from steady state)
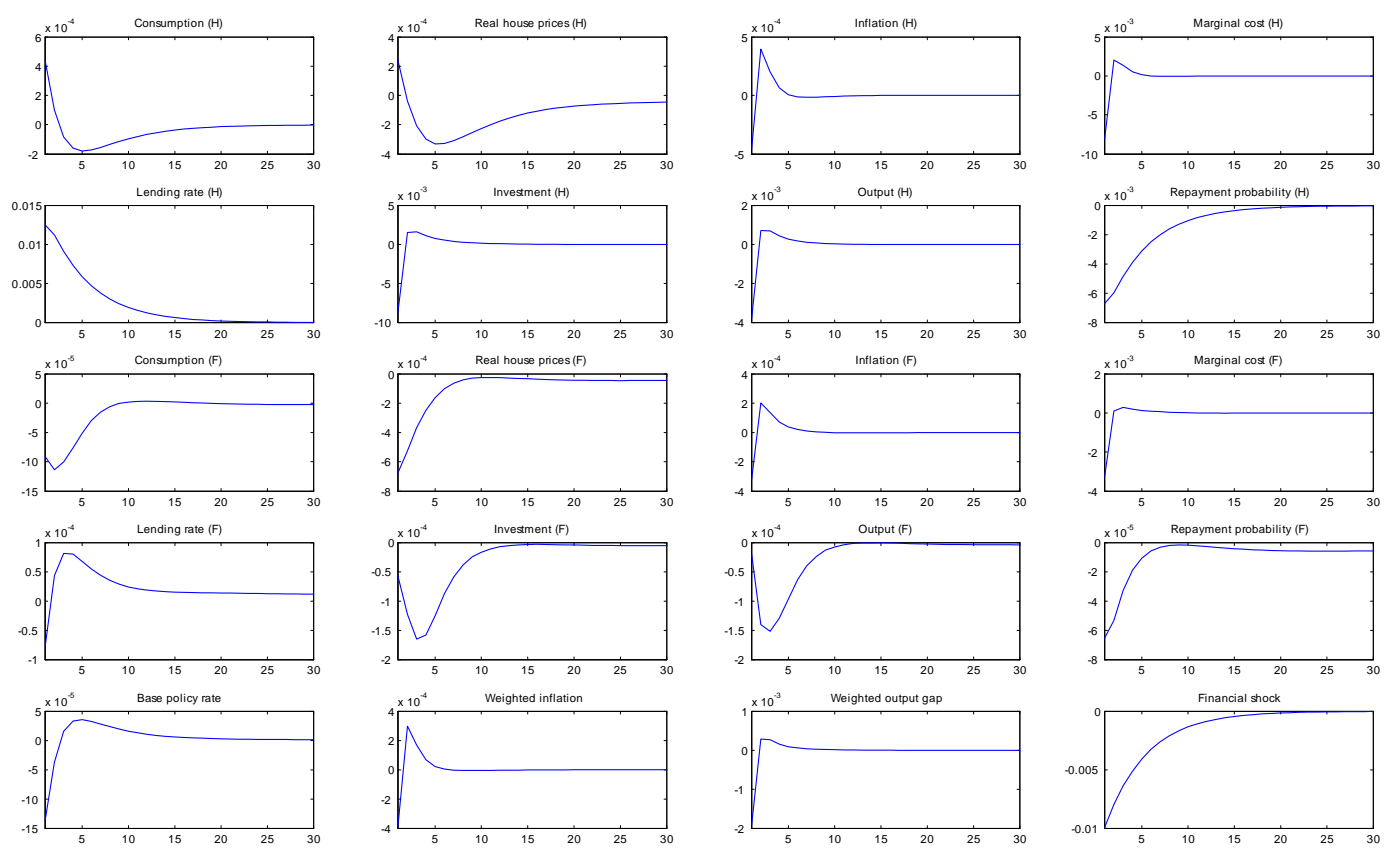

Note: See note for Figure 2. 
Figure 4

Centralized Regime, Uniform Required Reserve Ratio Productivity Shock

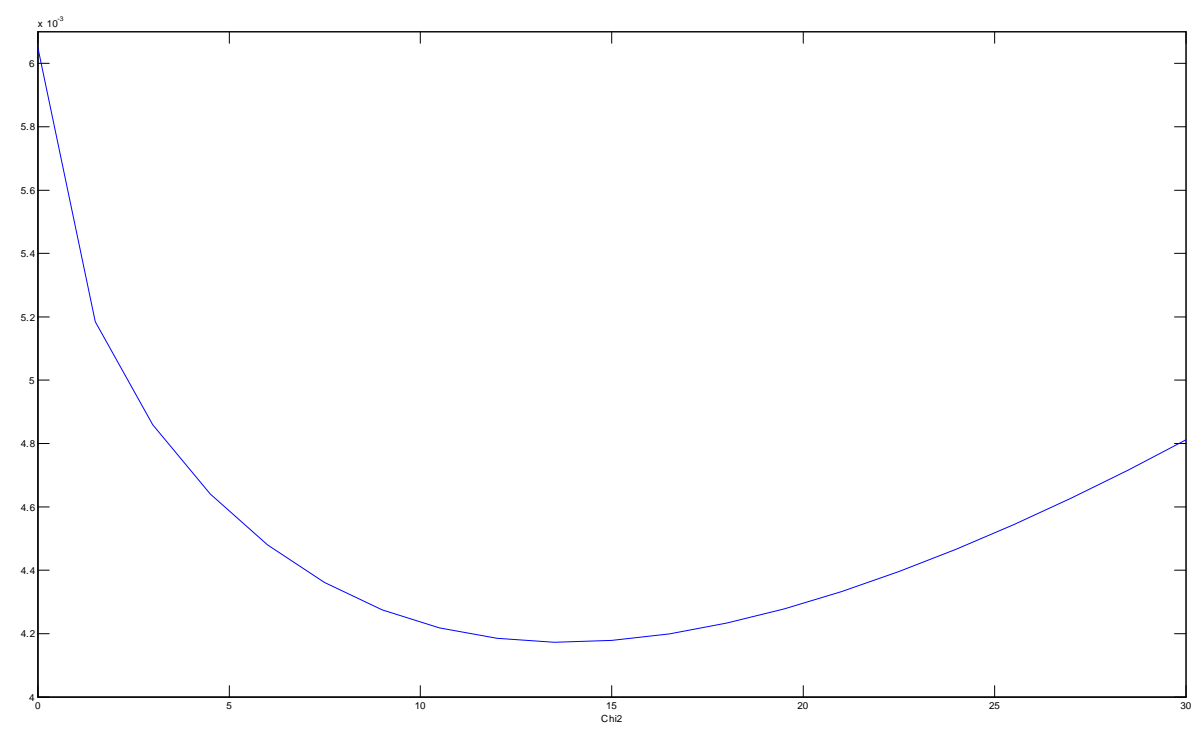

Financial shock

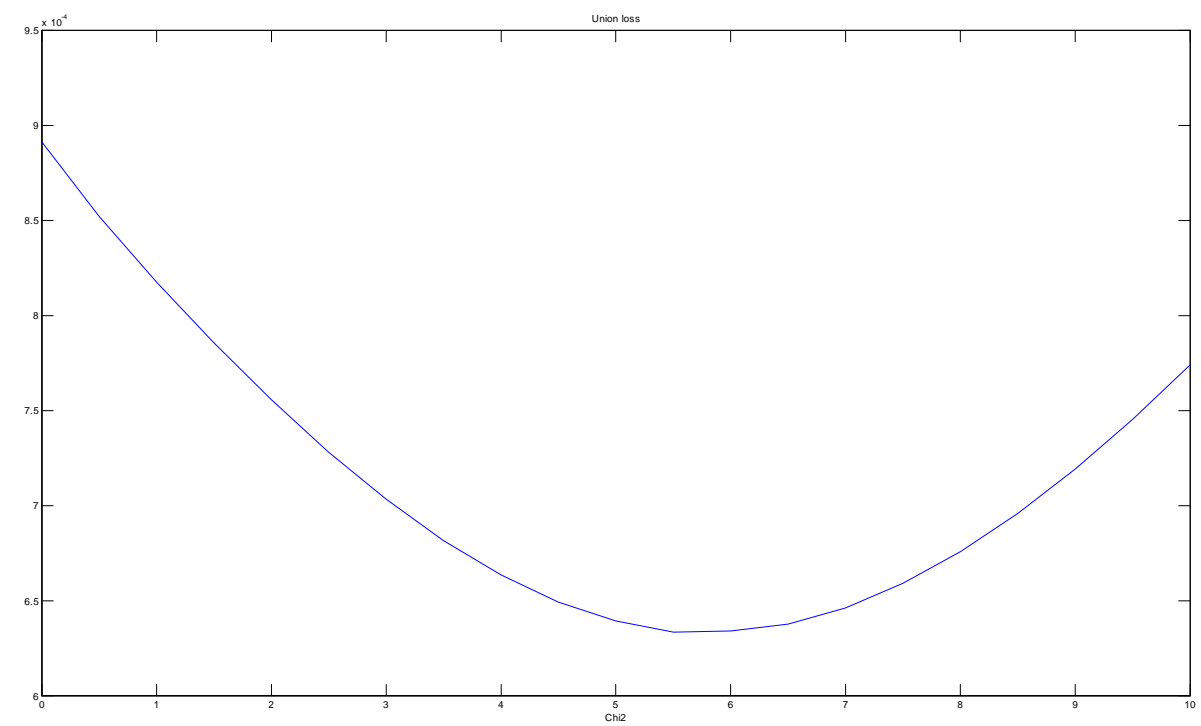

Note: In each panel the vertical axis represents the value of the union-wide policy loss function defined as a weighted average of the policy loss of the two members, under cooperation. 
Figure 5

Centralized Regime, Separate Required Reserve Ratio

Productivity Shock

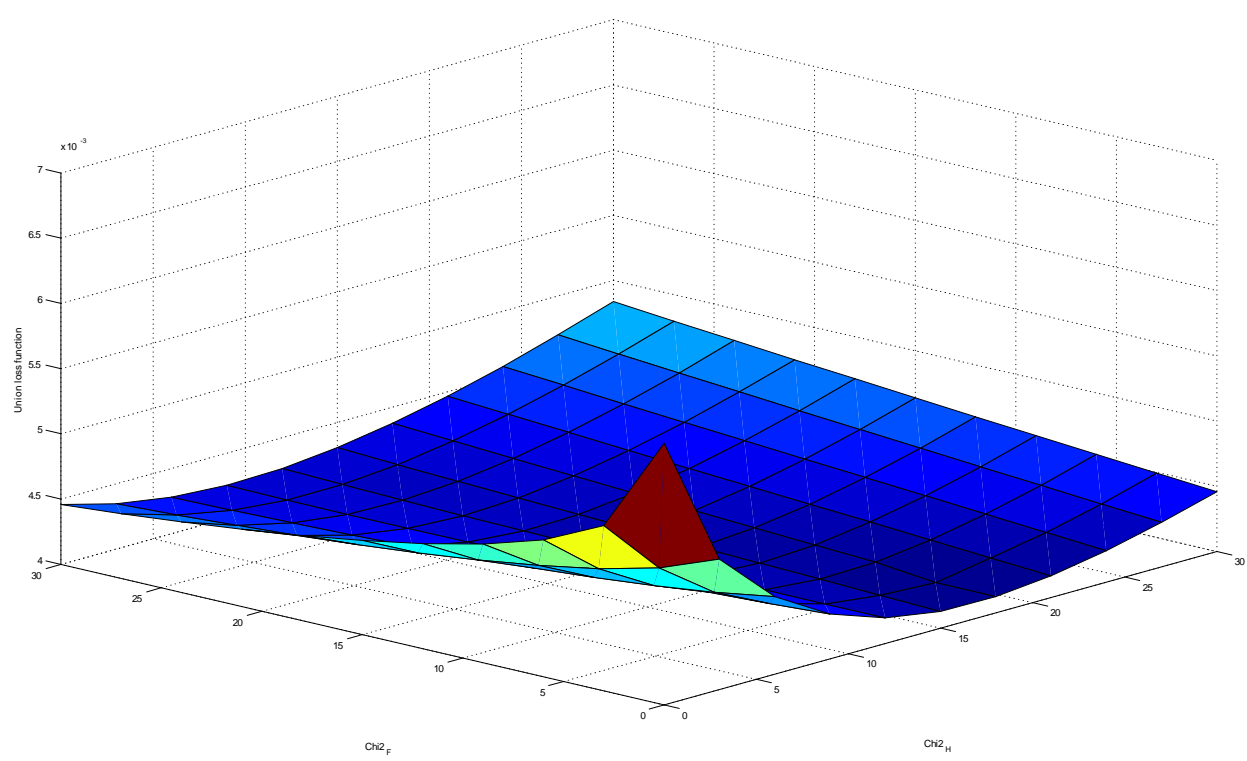

Financial shock

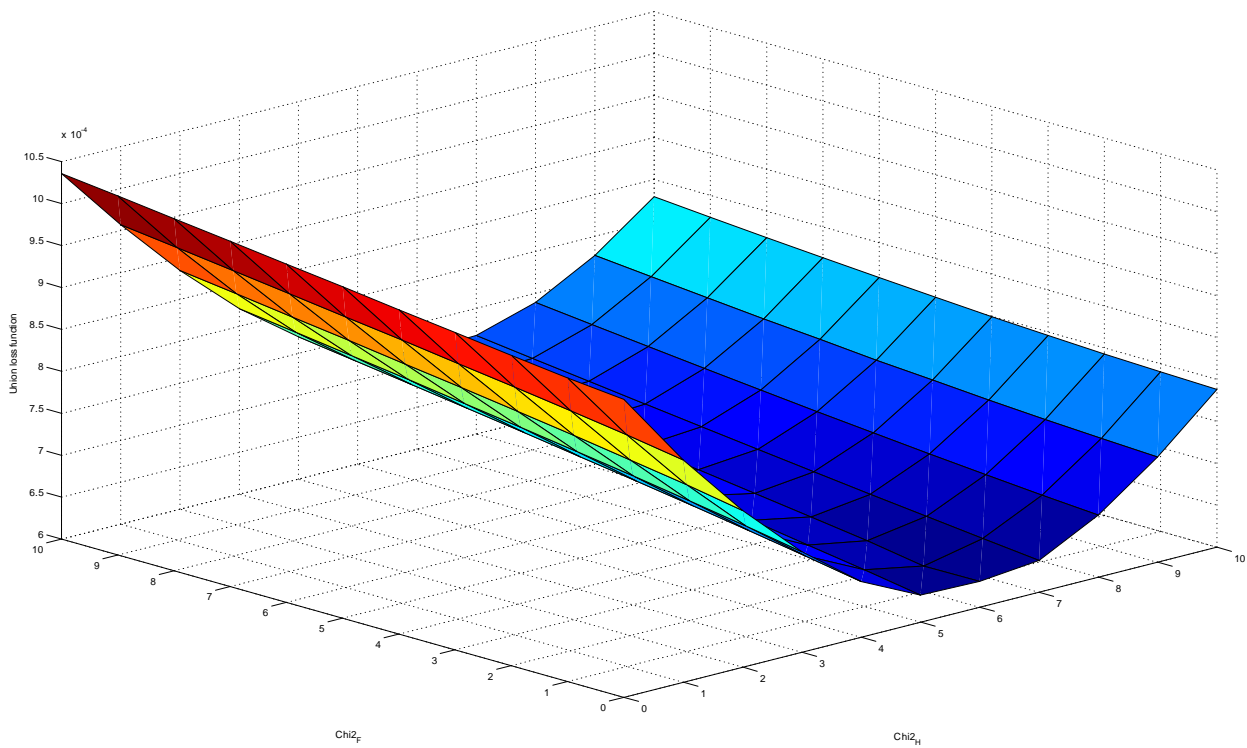

Note: See note for Figure 4. 
Figure 6

Union-wide Gains from Coordination, Separate Required Reserve Ratios

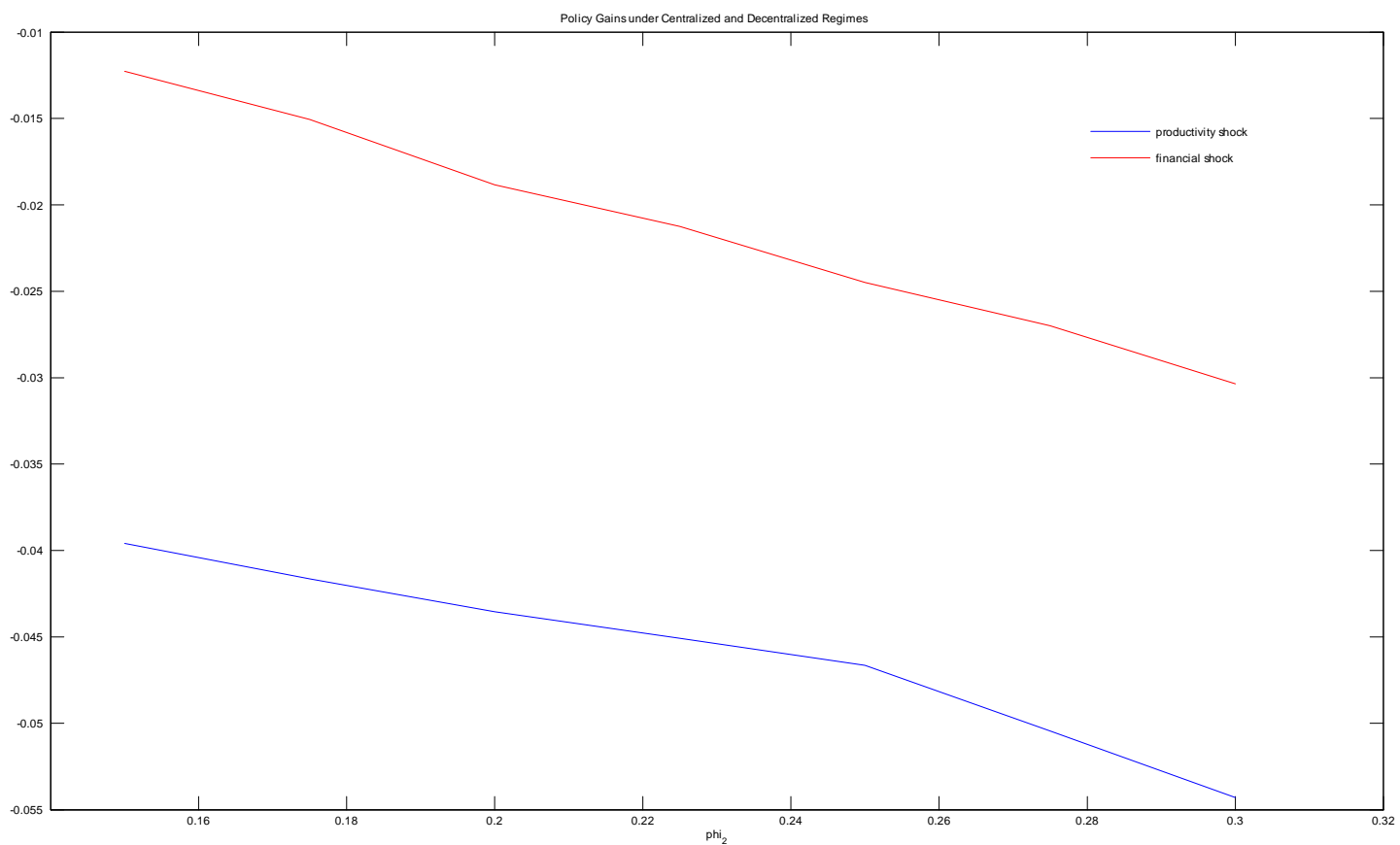

Note: The horizontal axis shows the behaviour of the elasticity of the repayment probability with respect to cyclical output, $\varphi_{2}$. The vertical axis shows the gain from coordination relative to Nash, when separate required reserve ratios are set by the common regulator. A negative number means a net policy gain from cooperation. 